$$
\begin{gathered}
\text { UNITED STATES } \\
\text { DEPARTMENT OF THE INTERIOR }
\end{gathered}
$$

GEOLOGICAL SURVEY

CHARACTERISTICS OF THE LANDSAT MULTISPECTRAL

DATA SYSTEM

By James V. Taranik

Open-File Report 78-187

Sioux Falls, South Dakota

January, 1978 
CONTENTS

Page

Abstract-- 1

Preface-- 3

Introduction- 3

Satellite Characteristics- 5

Orbit Characteristics of Landsats-1 and -2- 5

Sun Synchronous Orbit- 5

Variations in solar illumination- 13

Orbit stabilization-_- 16

Sidelap of Landsat coverage-_- 18

Importance of repetitive coverage for geologic

applications- 20

Landsat-1 and -2 payload-_- 22

The Landsat multispectral scanner-_ 26

Function of the multispectral scanner- 26

Formation of the MSS picture element- 33

Detection of ground features with the MSS- 33

Integration of ground spectral response-- 36

Effects of the atmosphere on landscape spectral

brightness- 39

Tape recording of Landsat data onboard satellite--_-_-_ 46

Landsat-1 and -2 data handling- 46

Characteristics of Landsat-1 and -2 data-- 55

Landsat imagery-- 55 
Figure 15. The electromagnetic spectrum with the visible range and reflected (solar infrared) range shown in detail- 25

16. Schematic drawing of the MSS- 26

17. Geometry and ground dimensions for fiber optic bundles at focal plane on MSS telescope-----

18. Relationship between maximum percent of radiance and digital count for MSS-_- 18

19. Maximum radiance for $10 \mathrm{w}$ and high gain modes on the MSS

20. Energy path for Landsat -1 and -2 data acquisition

21. Relationship between voltage and digital

count for a hypothetical scan line-_-_-_- 31

22. Scanning arrangement of the MSS- 32

23. Scanning pattern of the MSS on the Earth's surface-- 32

24. Formation of the MSS picture elements (PIXEL)--- 34

25. Detection of ground features with the MSS on Landsat-1 and -2 - Case 1-_- 34

26. Detection of ground features by the MSS on

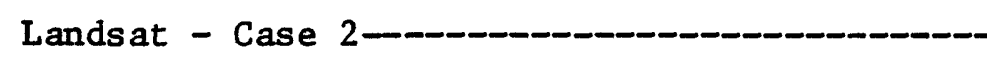

27. Detection of ground features by the MSS on Landsat - Case 
Figure 28. Spatial array of pixels and brightness values

(BV) from a portion of one Landsat band

29. Integration of spectral response within the

Landsat MSS IFOV. Atmospheric effects

not considered-- 38

30. Atmospheric effects on the energy path

between the sun and the Landsat satellite-- - -40

31. Effect of molecular scattering (Rayleigh) and sun angle on radiation transmitted to

Earth's surface-_an 41

32. Effect of aerosol scattering (Mie) and sun

angle on radiation transmitted to Earth's

surface-1-

33. Effect of water vapor absorption and sun angle on solar radiation transmitted through the atmosphere to the Earth's surface $(1 \mathrm{~cm}$ precipitable water)

34. Effect of water vapor absorption on transmittance of landscape brightness from Earth's surface to Landsat- 44

35. Integrated spectral brightness for a landscape covered with red sandstone and green vegetation, assuming no atmosphere and equal proportions of the cover types44 
Figure 36. Landscape brightness for an IFOV area of

the MSS that is composed of equal amounts

of red sandstone and green vegetation,

after the radiation has passed through

the atmosphere-m-n

37. MSS spectral record of landscape brightness in

four wavelength bands, for an MSS IFOV

containing equal amounts of red sandstone

and green vegetation-

38. Landsat data collection status- 47

39. Landsat-1 and -2 data flow 48

40. Landsat System mode of operations- 49

41. MSS data processing path at the Image Processing

Facility at Goddard Space Flight Center-- 51

42. Schematic diagram of the electron beam recorder

used to produce Landsat imagery- 52

43. Data processing path for Landsat-1 and -2

computer tapes- 54

44. Landsat image coverage. Latitude and longitude

lines drawn for an area in Colorado- 56

45. Annotation of Landsat-1 and -2 imagery-- 57

46. Landsat CCT format- 59

47. Procedures for digital image processing for

geologic applications-- 61 
Figure 48. Thermal portion of the electromagnetic spectru

49. Configuration of the fiber optic bundles in the focal plane of the MSS for Landsat-C---- 65

50. The Landsat-C band 8 picture element compared to picture elements for bands $4,5,6$, and 7 66

51. Schematic of the RBV system vidicon tube- 66

52. Three camera RBV system on Landsats-1 and 2--- 67

53. Two camera RBV systems planned for Landsat-C---- 68

54. Coverage of the Landsat-C RBV system-_- 69

55. Proposed data handling plan for Landsat-C data---- 72

56. Possible data handling plan for data produced

in the Landsat-D time frame- 73 
TABLES

Page

Table 1. Characteristics of the Landsat orbit- 7

2. The spectral wavelength intervals (bandpasses)

detected by the sensing systems on

Landsats-1 and -2- 24

3. Comparison of Landsat coverage with aircraft

coverage-n 58

viii 


\section{CHARACTERISTICS OF THE LANDSAT MULTISPECTRAL \\ DATA SYSTEM}

By James V. Taranik, U.S. Geological Survey

\section{ABSTRACT}

Landsat satellites were launched into orbit in 1972 and 1975. Additional Landsat satellites are planned for launch in 1978 and 1981. The satellites orbit the Earth at an altitude of approximately $900 \mathrm{~km}$ and each can obtain repetitive coverage of cloud-free areas every 18 days. A sun-synchronous orbit is used to insure repeatable illumination conditions. Repetitive satellite coverage allows optimal cover conditions for geologic applications to be identified. Seasonal variations in solar illumination must be analyzed to select the best Landsat data for geologic applications. Landsat data may be viewed in stereo where there is sufficient sidelap and sufficient topographic relief. Landsat-1 ceased operation on January 10, 1978. Landsat-2 detects. only solar radiation that is reflected from the Earth's surface in visible and near-visible wavelengths. The third Landsat will also detect emitted thermal radiation. The multispectral scanner (MSS) was the only sensing instrument used on the first two satellites. The MSS on Landsats -1 and -2 detect radiation which is reflected from a $79 \mathrm{~m}$ by $79 \mathrm{~m}$ area, and the data are formatted as if the measurement was made from a $56 \mathrm{~m}$ by $79 \mathrm{~m}$ area. 
The MSS integrates spectral response from all cover types within the $79 \mathrm{~m}$ by $79 \mathrm{~m}$ area. The integrated spectral signature often does not resemble the spectral signature from individual cover types, and the integrated signature is also modified by the atmosphere. Landsat-1 and -2 data are converted to $70 \mathrm{~mm}$ film and computer compatible tapes (CCT's) at Goddard Space Flight Center (GSFC); these are shipped to the EROS Data Center (EDC) for duplication and distribution to users. Landsat-C data will be converted to $241 \mathrm{~mm}$-wide film and CCT's at EDC. Landsat-D data will be relayed from the satellite directly to geosynchronous satellites and then to the United States from any location on Earth. 


\section{PREFACE}

The material in this report was largely developed from two references: the NASA Landsat Data Users Handbook and Thomas, 1975. The latter reference deals with the production and characteristics of Landsat-1 and -2 MSS computer compatible tapes. This report was prepared over a three-year period and is used to supplement a two-hour, slide-illustrated lecture and workshop exercise given for training programs in geological remote sensing at the EROS Data Center. S1ides of figures are available from the EROS Data Center by referencing Public Affairs office (PAO) numbers in the figure captions.

\section{INTRODUCTION}

The Landsat system was conceived by a group of scientists in the U.S. Department of Interior and the National Aeronautics and Space Administration (NASA). The exact data commemorating development of the idea for Landsat is difficult to ascertain because the ideas for such a system undoubtedly grew out of informal discussions. Beginning in 1963, the launching of Nimbus weather satellites spurred the development of Earth observations satellites. On October 21, 1966, the Under Secretary, Department of the Interior provided specifications to NASA for the first Earth Resources Survey Satellite to meet the needs of Interior and other resource agencies. One of the principal contributors to the concept of an Earth Resources Technology Satellite (ERTS) was Dr. William A. Fischer, now Senior Scientist for the Earth Resources Observation System (EROS) Program. Dr. Fischer and other 
U.S. Geological Survey geologists presented their ideas to the late Dr. William T. Pecora when he was Director of the Survey. When Dr. Pecora became Under Secretary for Interior, he took the lead in implementation of the EROS Program within the Department of Interior. The first satellite, initially called ERTS-A, used a Nimbus-type design that was modified to carry two sensor systems and a data relay system. The satellite was launched by a Thor-Delta rocket on July 23, 1972 from the NASA Western Test Range in Lompoc, California. Total weight of the launch vehicle was $133,400 \mathrm{~kg}$, and total weight of the satellite was $815 \mathrm{~kg}$. When the satellite achieved orbit, it was designated ERTS-1 and was expected to operate for a period of one year. Landsat-1 ceased operation on January 10, 1978 after five years of almost continuous operation.

A second satellite called ERTS-B was developed originally as a back-up to ERTS-1, but later served as a follow-on experiment, ERTS-B. Decisions related to the sensor package for ERTS-B and the exceptional performance of the multispectral scanning instrument on ERTS-1 delayed the launch of ERTS-B until January 22, 1975. When ERTS-B achieved orbit, it was named Landsat-2 by officials in NASA, and ERTS-1 was renamed Landsat-1. The satellite program was renamed the Landsat Program in January 1975 to permit it to be distinguished from a planned oceanographic satellite called Seasat, and other satellites in the Earth resources satellite program.

In 1975, funding was approved for a third experimental Earth observations satellite called Landsat-C. Landsat-C has a scheduled 
launch of Spring 1978, and the sensor systems in Landsat-C are somewhat different from those in the first two satellites.

Landsat -1 and -2 data are now being used operationally by a wide range of users in government and industry, and there is great pressure to transfer status of the Landsat program from an experimental to an operational mode. Funding has now been approved for the launch of a fourth satellite called Landsat-D. Landsat-D launch is scheduled for 1981, and NASA and the Department of Interior are now defining mission characteristics, data collection instrumentation, and data handling system in view of the developing requirements of users.

\section{SATELLITE CHARACTERISTICS}

The Nimbus weather satellite, designed over 15 years ago, is the basic design used for Landsats $-1,-2$, and the planned third satellite (fig. 1). The satellite is 3 meters high, 1.5 meters in diameter at the sensor ring, and 4 meters wide with the solar panels extended.

\section{ORBIT CHARACTERISTICS OF LANDSATS -1 and -2 Sun Synchronous Orbit}

Landsat satellites are launched into a near-polar orbit at an altitude of approximately $900 \mathrm{~km}$. The altitude of the satellite varies between $880 \mathrm{~km}$ and $940 \mathrm{~km}$ (table 1). The orbits of the Landsat satellites are sun synchronous (fig. 2). The angle between the sun, center of the Earth, and the satellite is maintained at 37.5 degrees as the Earth orbits the sun, and the orbital plane of the satellite is 


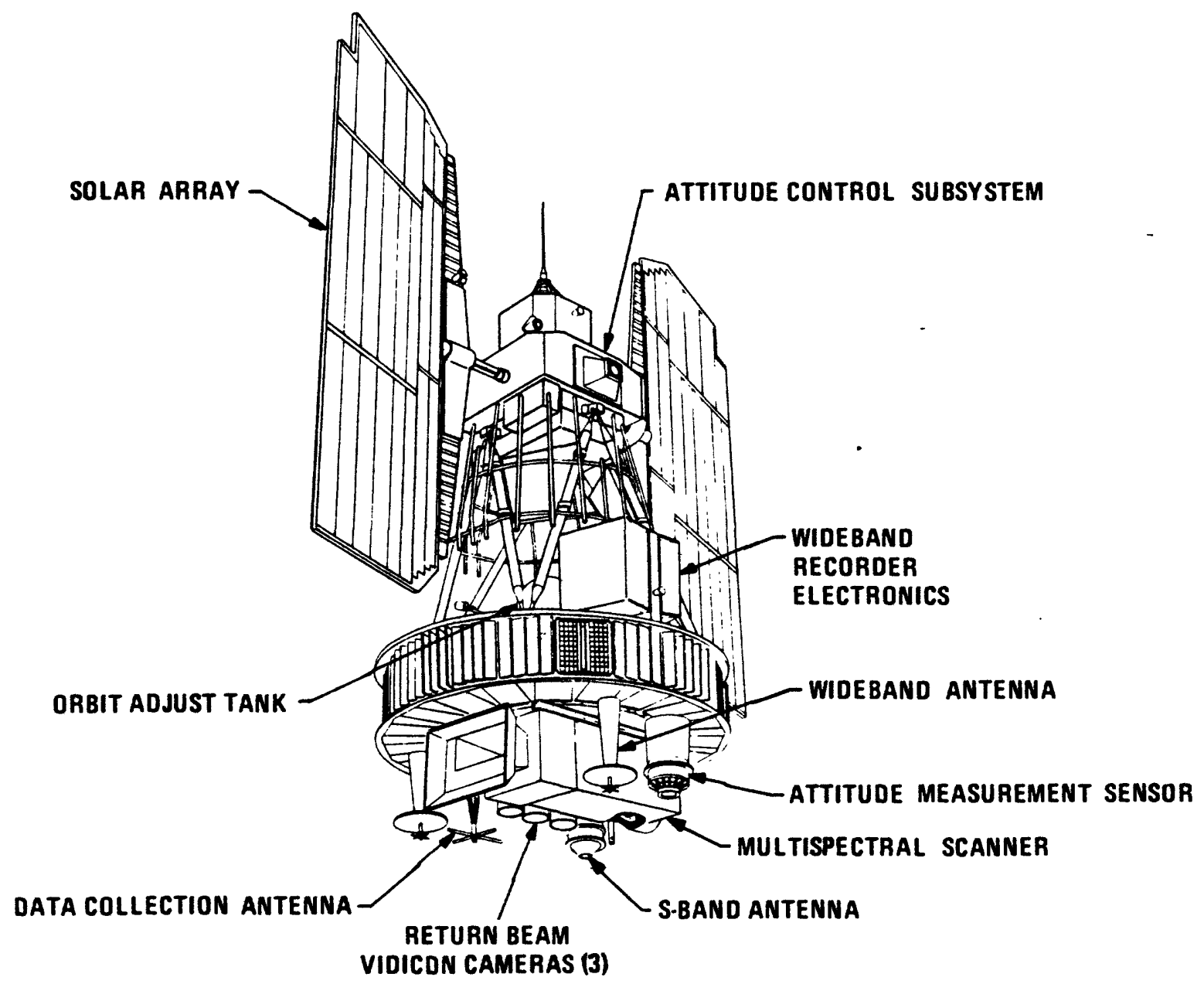

Figure 1: Nimbus-design with Landsat configuration. From NASA Landsat Data Users Handbook. 
Table 1: Characteristics of the Landsat orbit

Orbital Parameter

Semi-major axis

Inclination

Period

Eccentricity

Time of equatorial crossing

Coverage cycle

Duration of cycle

Distance between adjacent tracks at the equator

Distance between successive tracks at the equator

Altitude
Actual Orbit

$7285.82 \mathrm{~km}$

$99.114 \mathrm{deg}$

$103.267 \mathrm{~min}$

.0006

$9: 42 \mathrm{a} \cdot \mathrm{m} . \underline{1 /}$

18 days $2 /$

251 revs

$159.38 \mathrm{~km}$

$2,760 \mathrm{~km}$

$880-940 \mathrm{~km}$
Mode1 Orbit

$99.092 \mathrm{deg}$

$103.267 \mathrm{~min}$
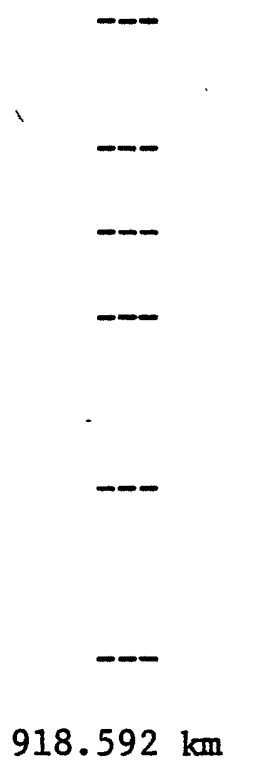

I/ Landsat-1 8:30 a.m., March 1977; Landsat 2, 9:00 a.m., and was adjusted to 9:30 a.m. by December 1977. Landsat-1 ceased to operate on January $10,1978$.

$2 /$ Coverage cycle for one satellite 18 days, changed to 9 days for both Landsats-1 and -2 until March 1977 when the coverage cycle became 6 and 12 days. 


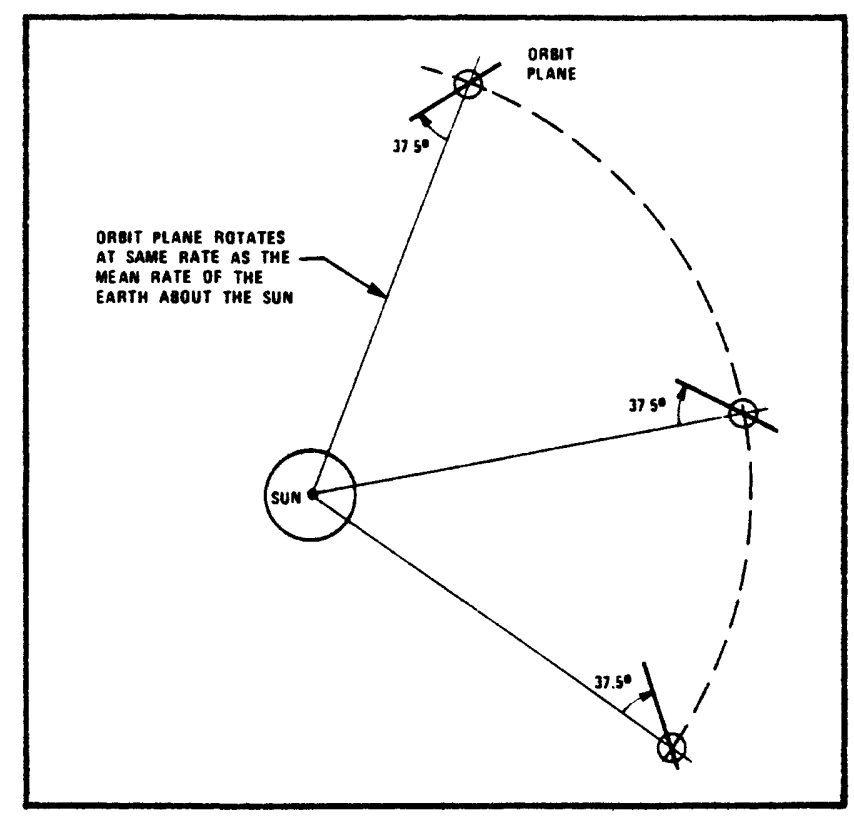

Figure 2: Sun synchronous Landsat orbit. From NASA Landsat Data Users Handbook. PAO Number: E-6175-35

inclined 99 degrees, measured clockwise from the Equator (fig. 3). This type of orbital configuration insures repeatable sun-illumination conditions. Repeatable illumination conditions are desirable to mosaic adjacent tracks of imagery and to compare yearly changes in landscape cover.

The satellite crosses the Equator every 103 minutes; during this time, the Earth rotates a distance of $2,760 \mathrm{~km}$ under the satellite at the Equator. If the first satellite track covers New York City in the eastern United States, the next track is close to Sioux Falls, South Dakota (fig. 4). When the satellite makes 14 orbits, 24 hours have elapsed, and the next westward track of data is acquired (fig. 4). 


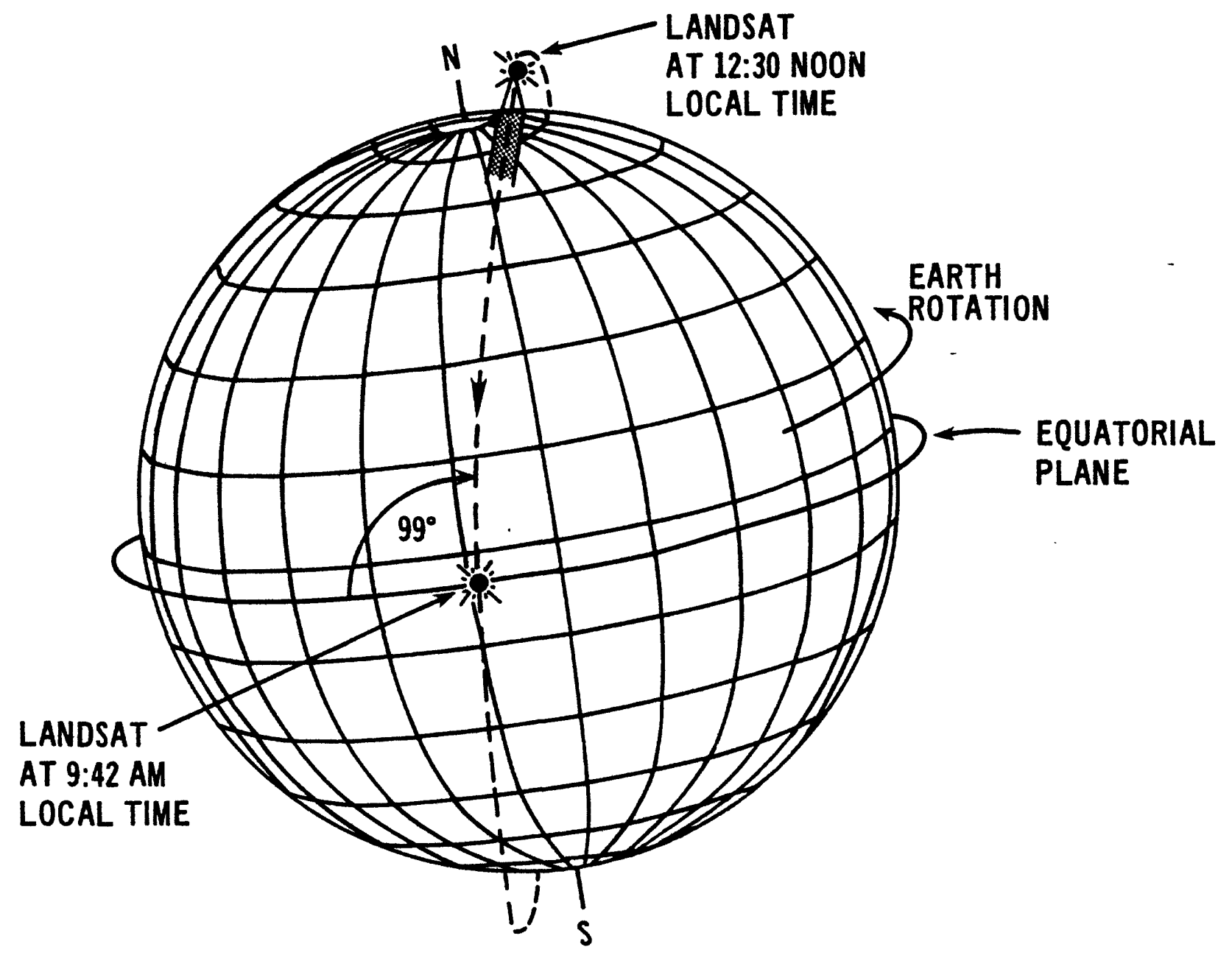

Figure 3: Inclination of Landsat orbit to maintain sun synchronous orbit. PAO Number: E-6174-35 


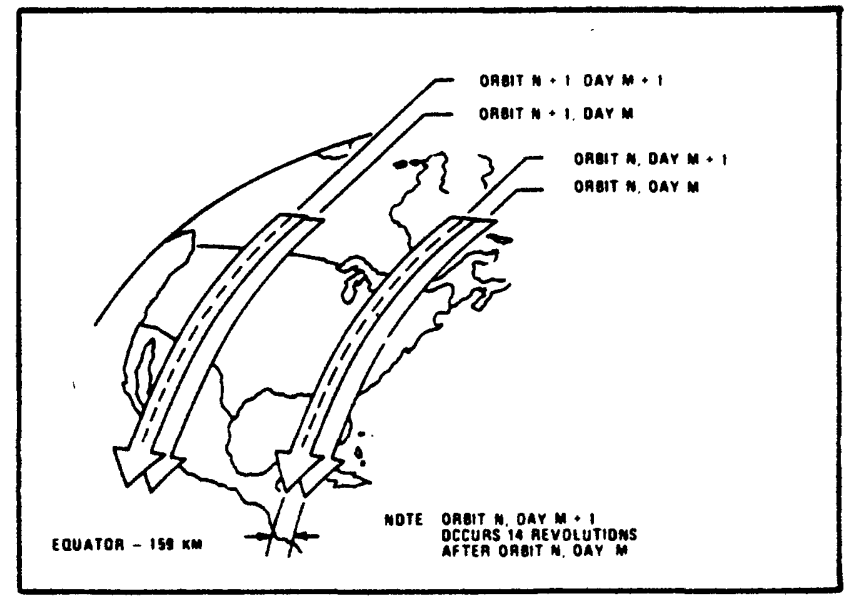

Figure 4: Orbital coverage characteristics of Landsat. From NASA Landsat Data Users Handbook. PAO Number: 3-6177-35 
In 18 days one satellite obtains coverage of nearly the entire Earth's surface, providing weather conditions permit and the satellite sensing systems are on (fig. 5). The satellite crosses near the North Pole about 3:00 p.m. (1500 hours) local time. As the satellite travels southward, gathering data on the sunlit side of the Earth, it crosses Alaska about 10:00 a.m., and then the equator at 9:42 a.m. 1ocal time.

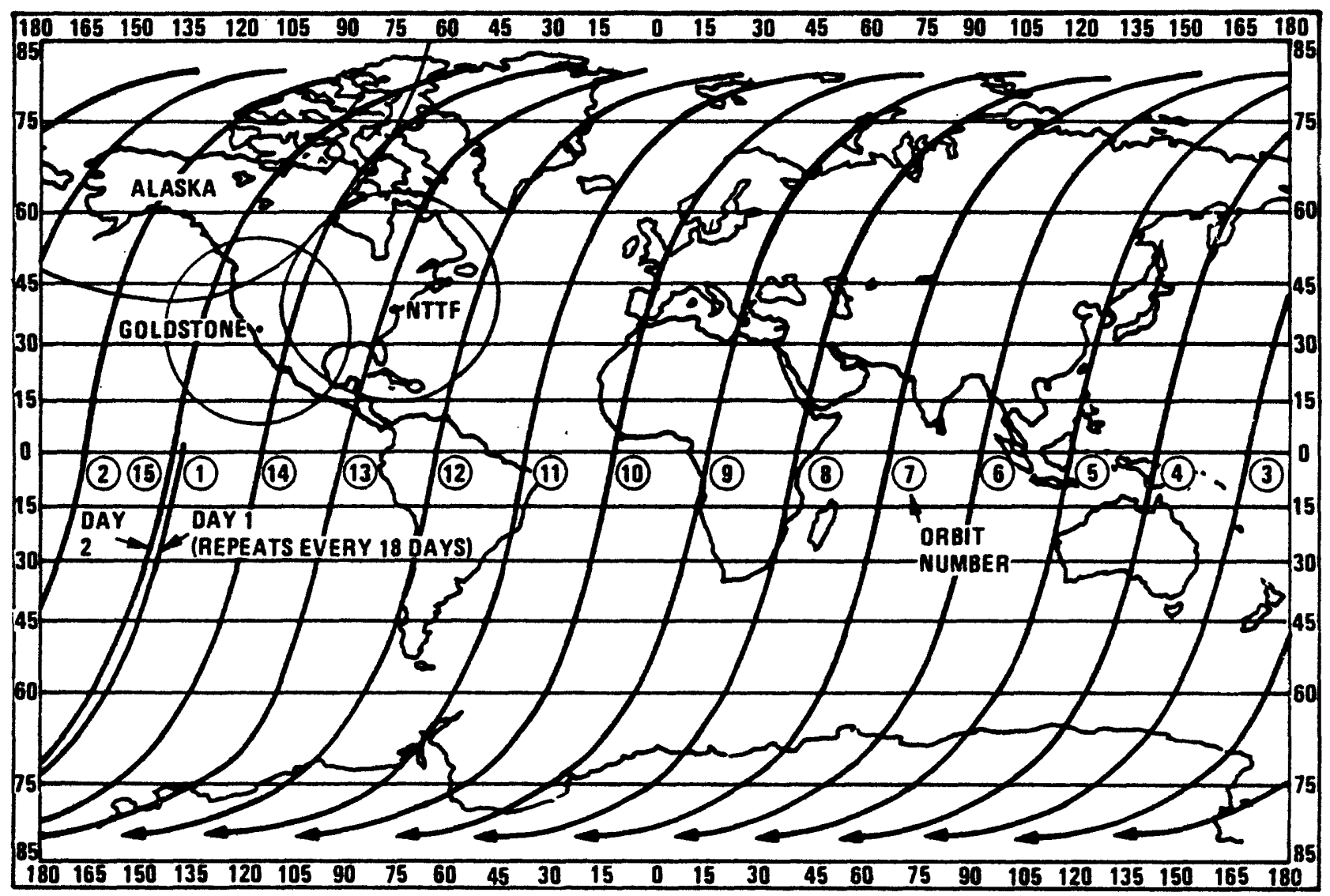

Figure 5: Landsat orbital tracks for one day of coverage. From NASA Landsat Data Users Handbook. 
As the satellite continues southward, it crosses Chile at 9:00 a.m. and the South Pole at 3:00 a.m. local time (fig. 6).

Landsat-2 was launched so that it would follow Landsat-1 by 9 days in orbit. Therefore, with two satellites, 9-day coverage of the Earth between $82^{\circ} \mathrm{N}$. and $82^{\circ} \mathrm{S}$. latitude was possible, providing the weather permitted observations and the satellites' instruments were on.

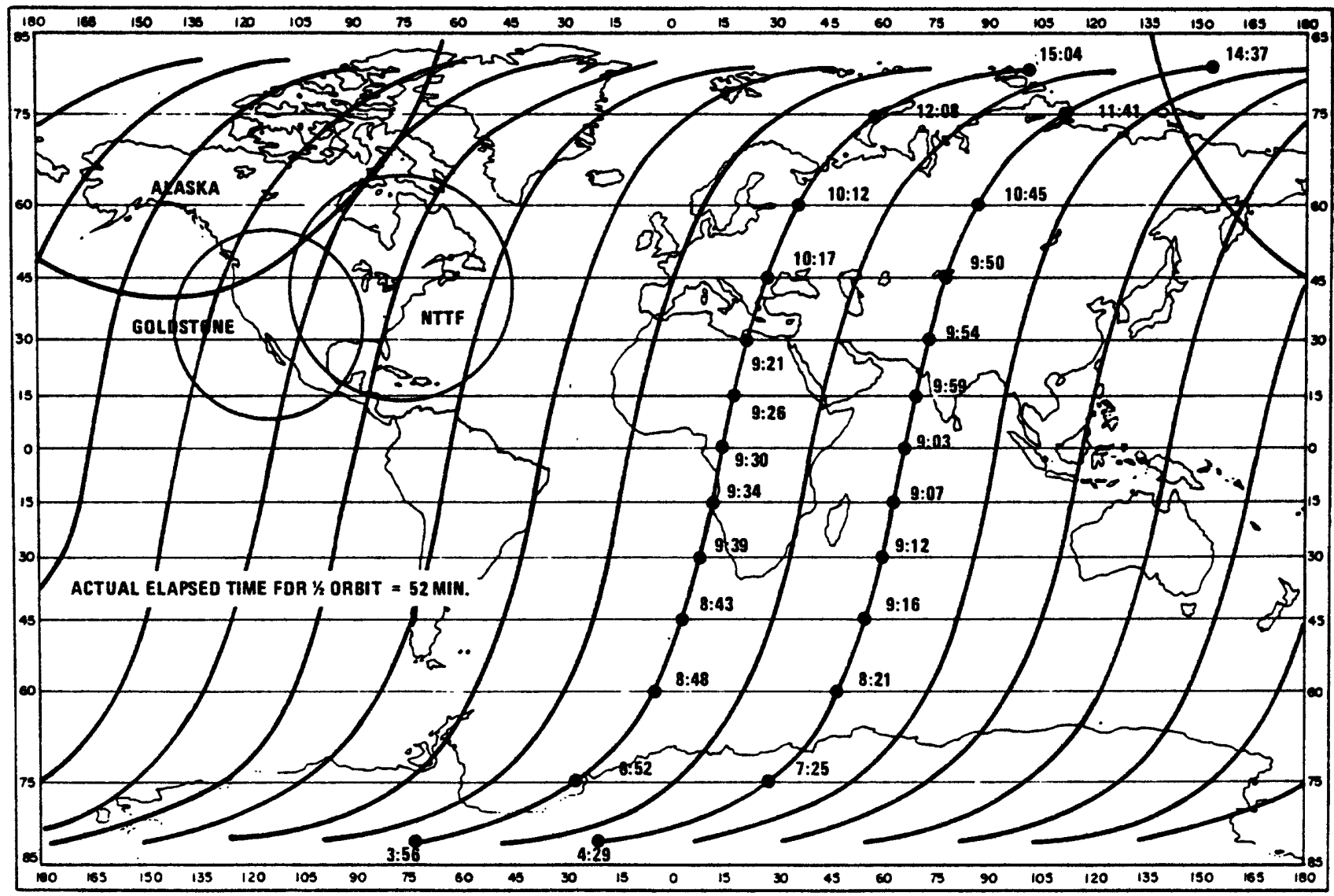

Figure 6: Variations in local time of data acquisition. From NASA Landsat Data Users Handbook. PAO Number E-6391-35 


\section{Variations in Solar Illumination}

Landsat has a sun-synchronous orbit, which insures repeatable illumination conditions. This does not mean that illumination conditions are uniform along a Landsat ground track, or that conditions are unchanged throughout the year. In the Sioux Falls area, the Sun's rays strike the Earth at angles close to $20^{\circ}$ in December, and at $60^{\circ}$ in July. Solar elevation angle relationships are shown in figure 7 . Along a single January orbit the solar elevation angle changes from $4^{\circ}$ in Alaska to $45^{\circ}$ near the equator.

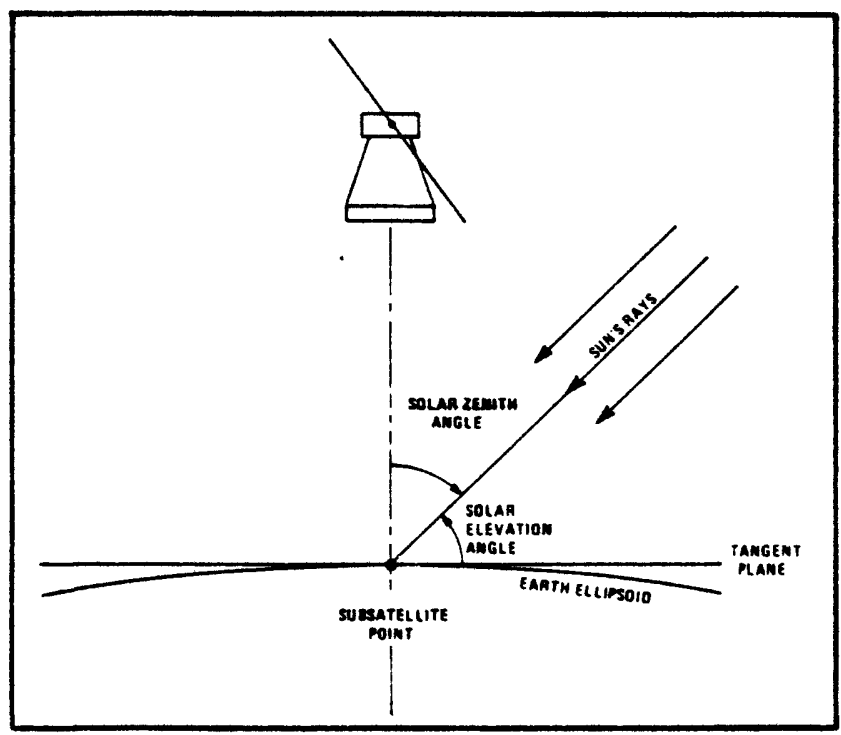

Figure 7: Sun illumination relationships. From NASA Landsat Data Users Handbook. PAO Number: E-6314-35 
Optimum sun angles for landform and drainage analysis in terrain of moderate relief are close to $25^{\circ}$. In mountainous terrain, cover conditions are best interpreted from data acquired with the highest possible sun angle to minimize topographic shadowing. Low solar illumination is desirable for flat, highly-reflective desert terrain. Relationships between latitude of satellite data acquisisiton, solar elevation angle, and date of data acquisition are shown in figure 8 .

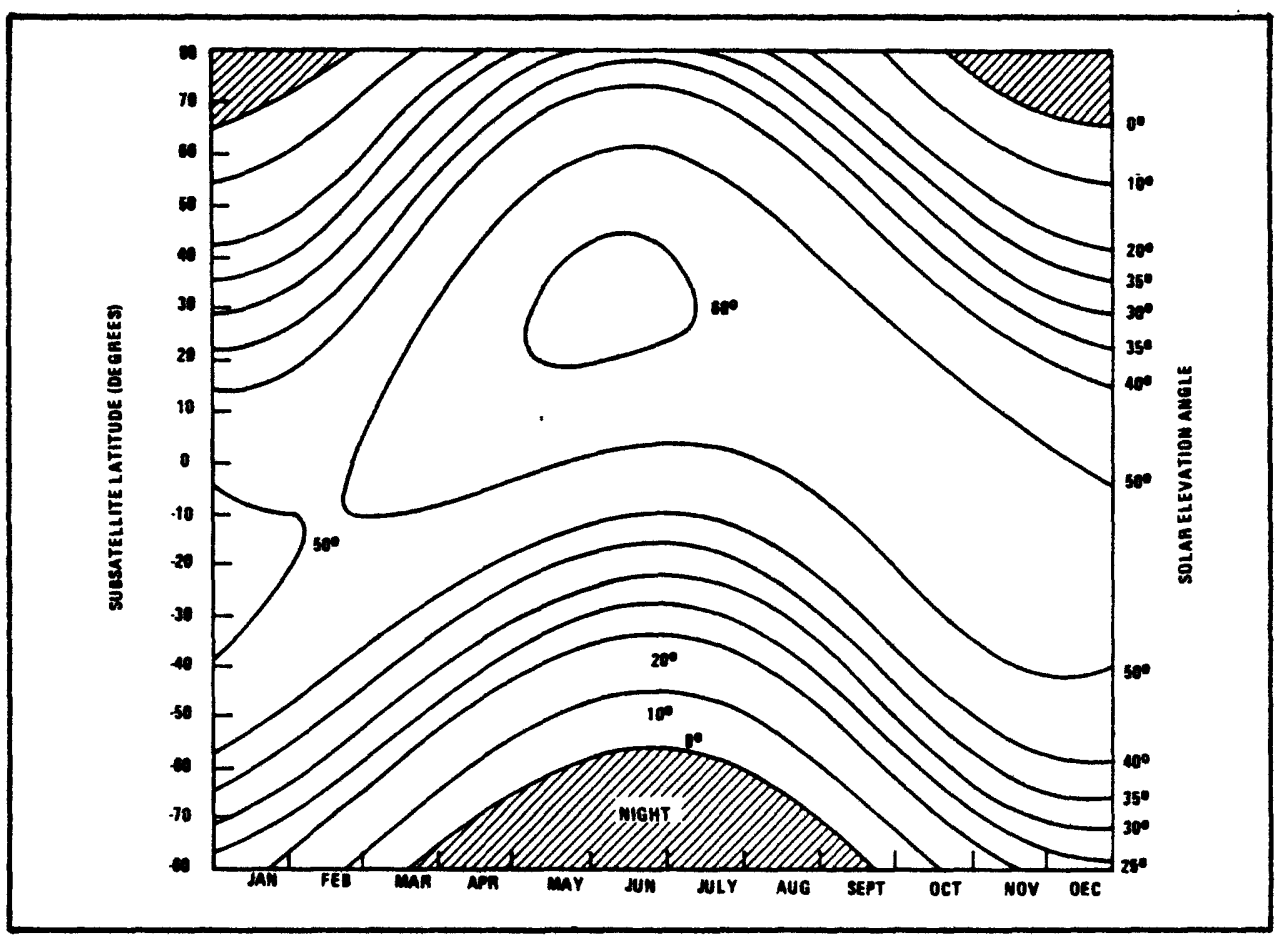

Figure 8: Solar elevation angles at different latitudes and different times of year for the Landsat satellite. NASA Landsat Data Users Handbook 
The azimuth of solar illumination also changes with season and latitude (fig. 9). Different directions of solar illumination cause different illumination conditions for terrain features of the Earth's surface. These relationships can influence an analysis and interpretation of landscape features, particularly topographic lineaments (Taranik and Trautwein 1977, p. 775).
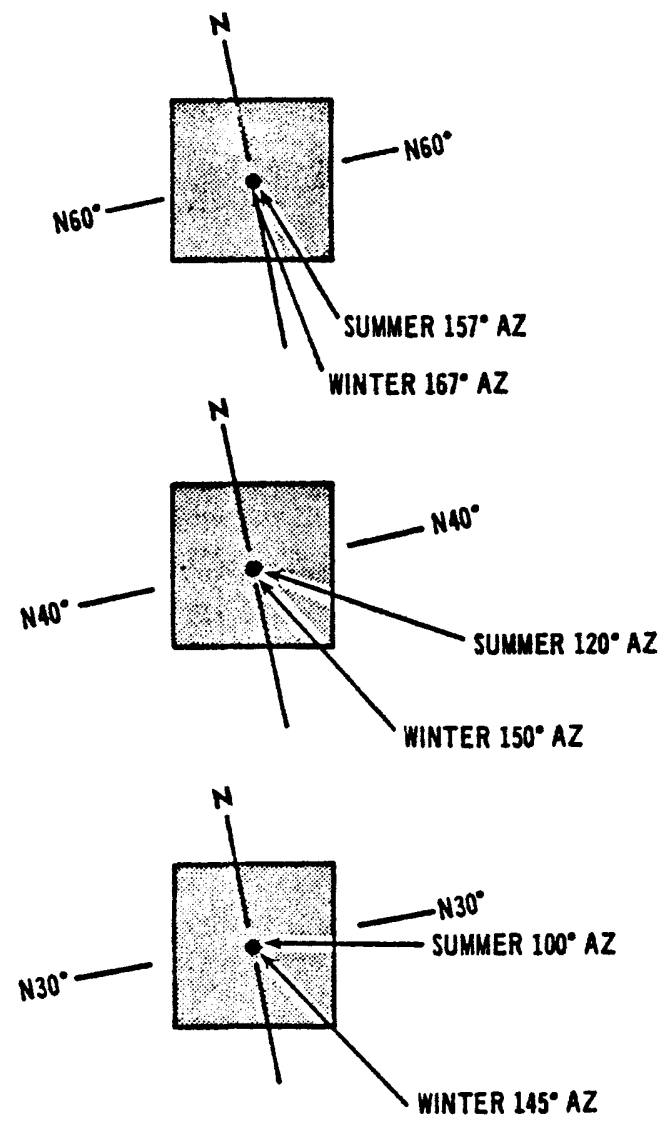

Figure 9: Variations in azimuth of solar illumination with season and latitude. PAO Number: E-6181-35. 


\section{Orbit Stabilization}

Landsat satellites are stabilized for pitch, yaw, and roll by a system of flywheels and rate gyros. This type of stabilization maintains the attitude of the satellites with respect to the Earth's surface. Satellite orbits are configured to offset the gravitational forces of the Earth-Moon-Sun systems; some orbital precession does occur, however, and the orbit must be adjusted so there will be nominal repetitive coverage within each ground swath. These adjustments are accomplished with a gas reaction jet system. Orbital precession and variations in satellite attitude cause variations in the area covered by repetitive overpasses (fig. 10). Variations in altitude of the satellite introduce variations in scale of the data. Corrections must be applied for these geometric distortions if Landsat data are to be registered (see Taranik, in press, for a discussion of registration of Landsat data).

The orbit of Landsat-1 could no longer be stabilized by the gas reaction jet system in 1976, and the satellite orbit was allowed to continue orbital processing until it again coincided with the orbit of Landsat-2. This procedure resulted in an earlier equatorial crossing time for Landsat-1 and caused repetitive coverage by the two satellites to occur at 6- and 12-day intervals, instead of 9-days throughout most of 1976. The earlier equatorial crossing time for Landsat-1 means that lower sun angles of illumination were available beginnings in Spring of 1977 until January 10, 1978, when Landsat ceased to function. These low illumination angles should permit better analysis of areas 


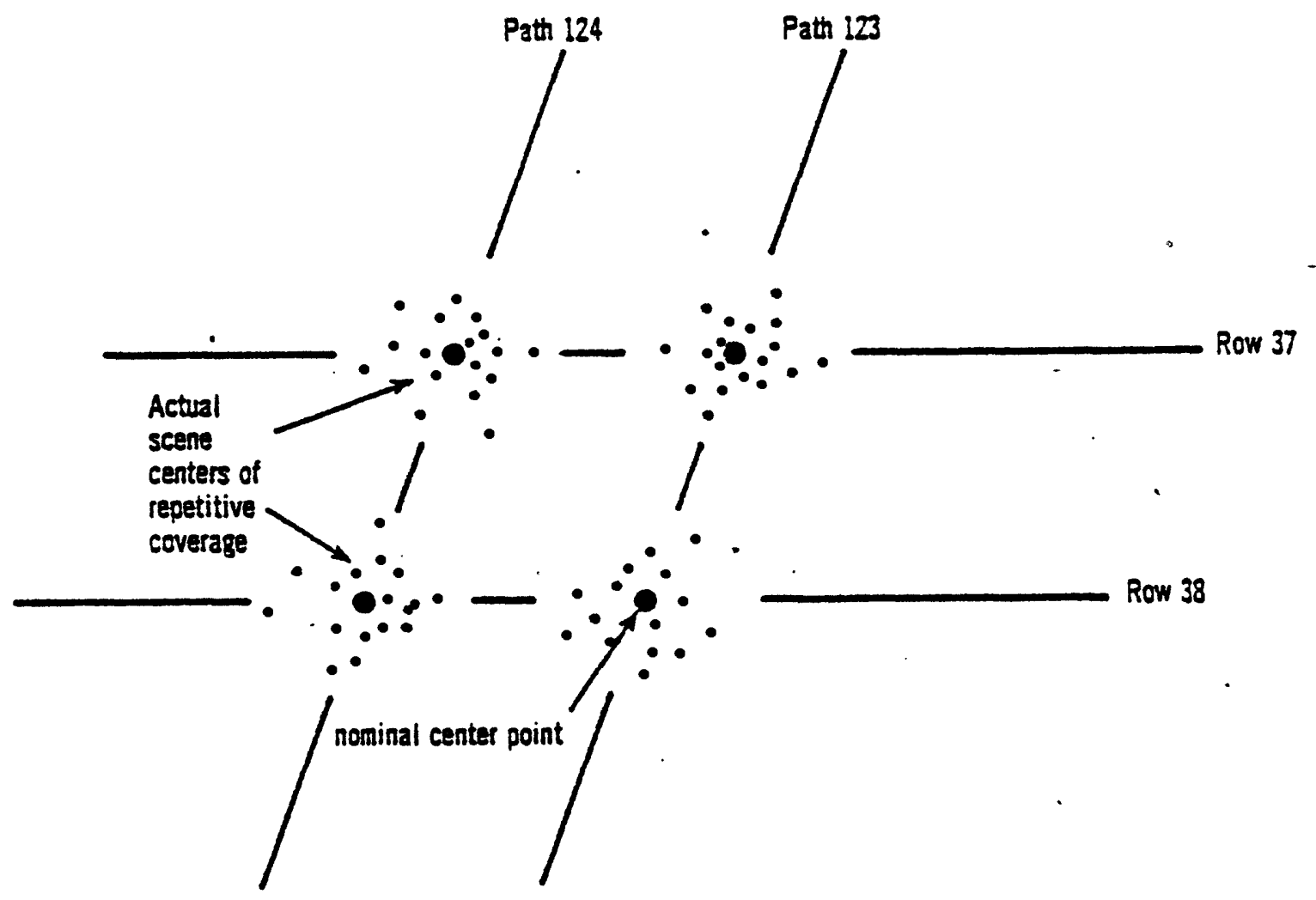

Figure 10: Relationship of actual scene centers to nominal center points for Landsat scenes acquired on a repetitive basis. PAO Number: E-6180-35 
having low topographic relief.

\section{Sidelap of Landsat Coverage}

Because orbital tracks of the satellite converge at the Poles and diverge at the equator, the amount of sidelap between adjacent ground swaths varies from over $60 \%$ in Alaska, to $35 \%$ in South Dakota, to $14 \%$ at the equator (figs, 11, 12, and 13). Where sidelap and topographic relief are sufficient (usually $200 \mathrm{~m}$ or more), Landsat images can be analyzed using stereoscopic viewing (Welch and Lo, 1977).

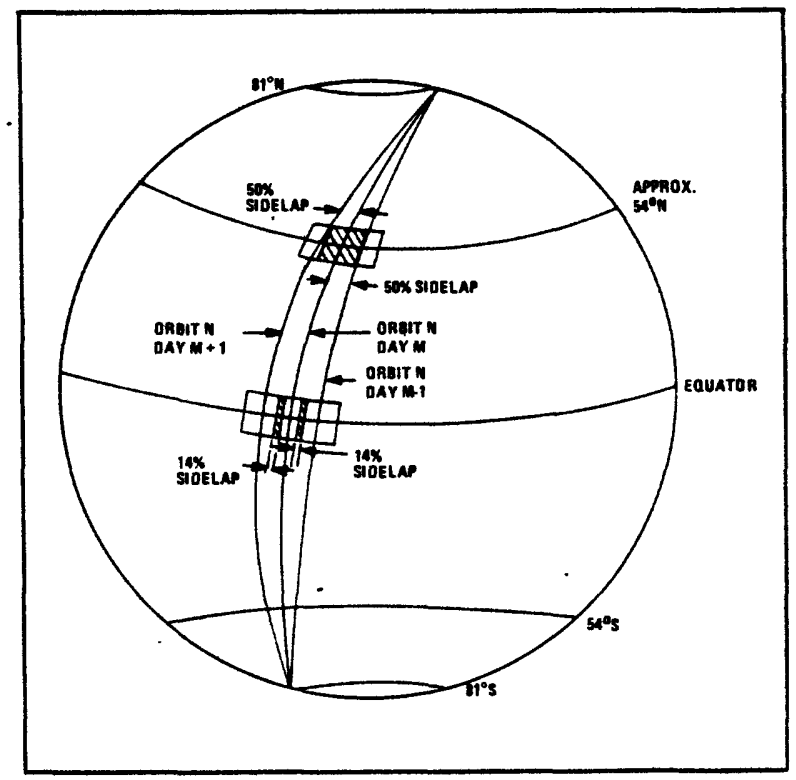

Figure 11: Orbital coverage of adjacent tracks. NASA Landsat Data Users Handbook. PAO Number: E-6312-35 


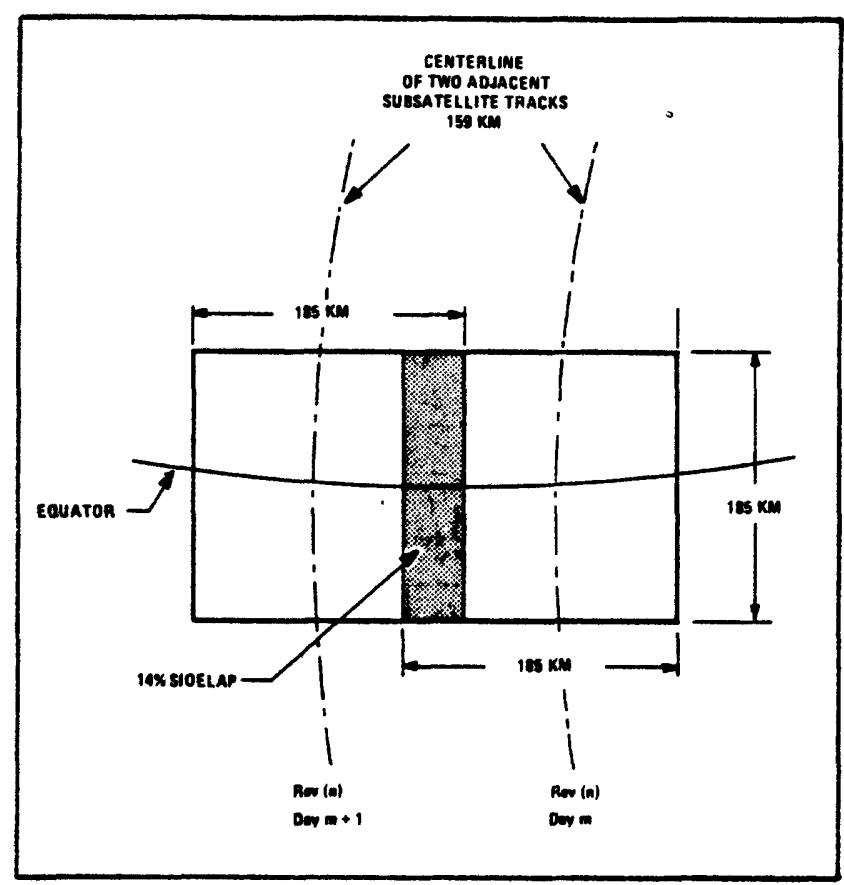

Figure 12: Sidelap between adjacent Landsat images at the equator. From NASA Landsat Data Users Handbook. PAO Number: E-6390-35 


\begin{tabular}{|c|c|}
\hline $\begin{array}{c}\text { Latitude } \\
\text { (deg) }\end{array}$ & $\begin{array}{c}\text { Image Sidelap } \\
\text { (\%) }\end{array}$ \\
\hline 0 & 14.0 \\
10 & 15.4 \\
20 & 19.1 \\
30 & 25.6 \\
40 & 34.1 \\
50 & 44.8 \\
60 & 57.0 \\
70 & 70.6 \\
80 & 85.0 \\
\hline
\end{tabular}

Figure 13: Relationships between latitude of Landsat data acquired and image sidelap. From NASA Landsat Data Users Handbook. PAO Number: E-6313-35.

\section{Importance of Repetitive Coverage for Geologic Applications}

Before the Landsat satellites were launched, repetitive coverage was considered by some to be unnecessary for most geologic applications. Geology does not change much between repetitive satellite overpasses; however, landscape cover conditions can change with the seasons, and over periods of years.

The importance of repetitive coverage for geologic investigations is illustrated by recent studies of Pleistocene materials and landforms in the upper Midwest. The Iowa Geological Survey first began to investigate the utility of mapping Quaternary landscape features in cooperation with the U.S. Geological Survey in 1972. In the first year of the investigation, the only cloud-free coverage of the portions 
of Iowa being examined occurred in July and August of 1972 and the investigators reported the Landsat data appeared to be of little value in mapping Quaternary relationships. Later, Morrison (1976) found that early June 1973 imagery of the Des Moines area showed interesting landscape features that were related to the last advance and retreat of continental glaciers from Iowa.

In the period 1974 through 1976, a team of investigators from the University of Iowa and the EROS Data Center began evaluating seasonal coverage of northwestern Iowa with Landsat imagery. Monthly coverage of northwestern. Iowa was not possible until four years of data were acquired by two Landsat satellites; this complete coverage would not have been acquired until late 1977 with one satelite. Data acquisition was limited by frequent clouds or haze over the areas of interest. Analysis of the seasonal coverage (Lucas and Taranik, 1977) showed that late April to early May imagery provided the best display of Quaternary materials and landforms in the upper Midwest.

Many landscape features produced by continental glaciation are of dimensions that require several Landsat images to properly display them. A regional mosaic of late April - early May imagery was started in 1975, but it could not be completed until late 1976. The mosaic contained images acquired over a 5-year period by the two different Landsat satellites. For many areas, only one acceptable frame of imagery was acquired during 5 years of coverage by two satellites (Lucas and Taranik, 1977). 
Many geological problems require analysis of imagery from several different seasons. December imagery of Tucson, Arizona is useful for landform and drainage analysis. Springtime imagery of Tucson provides important information for hydrologic analysis because of the close association of some springtime vegetation with a shallow water table and areas of ground water discharge. A comprehensive geological analysis of the hydrogeology of the Tucson area requires imagery from two different seasons (Taranik and Trautwein, 1977).

\section{LANDSAT-1 AND -2 PAYLOAD}

The satellite payload for Landsats -1 and -2 consists of two imaging instruments called the multispectral scanner (MSS) and the return beam vidicon ( $R B V)$, the data collection system (DCS) receiver and transmitter, and two wide band video tape recorders (WRVTR'S), (Fig. 14). Total weight of the payload is $240 \mathrm{~kg}$. Because of problems with the tape recorders on Landsats -1 and -2 , little RBV data are available. DCS is a real-time data relay system which can relay as many as 8 ground measurements to Goddard Space Flight Center, one to three times every 12 hours. The DCS has been used to monitor volcanoes, hydrologic phenomena, and production platforms in the Gulf Coast. Persons interested in this system should consult the NASA Landsat Data Users Handbook and the NASA Data Collection System Handbook for ERTS.

The spectral-wavelength intervals (bandpasses) detected by the sensing systems on Landsats -1 and -2 are shown in Table 2. A diagram of the electromagnetic spectrum is shown in figure 15 for reference. 


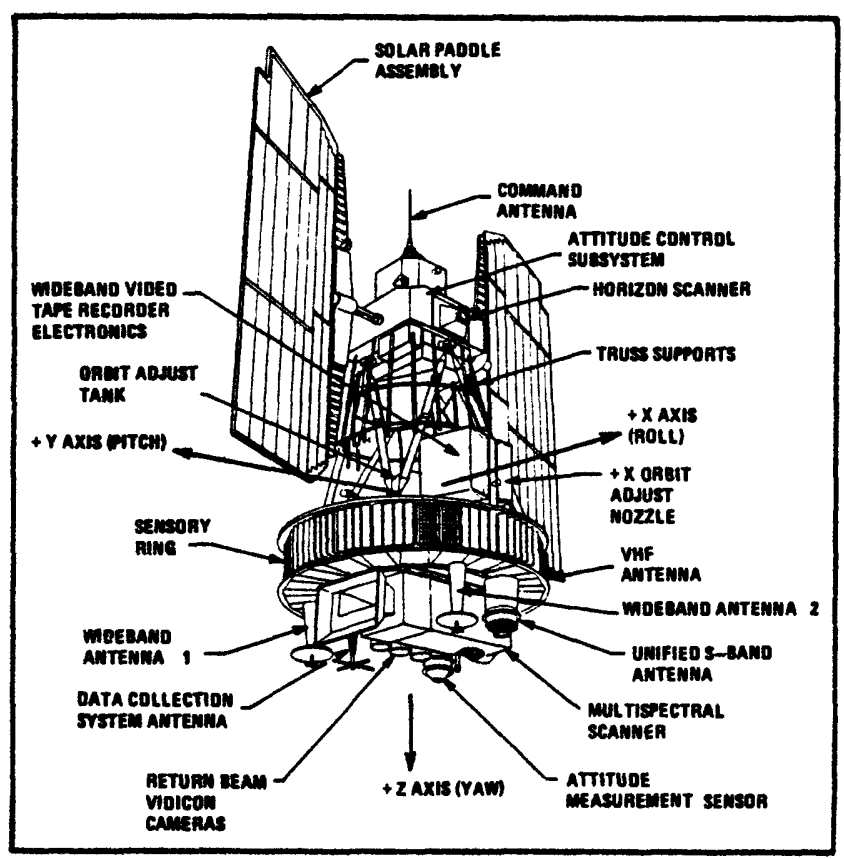

Figure 14: Payload for Landsats -1 and -2 . From NASA Landsat Data Users Hand book. 
Table 2: The spectral wavelength intervals (band passes) detected by the sensing systems on Landsats -1 and -2

\begin{tabular}{|c|c|c|c|c|}
\hline $\begin{array}{c}\text { Data } \\
\text { Channel }\end{array}$ & System & Type of Radiation & Wavelength & NASA Code \\
\hline 1 & $\mathrm{RBV}$ & Visible, yellow-green & $0.475-0.575 \mu \mathrm{m}$ & Band 1 \\
\hline 2 & RBV & Visible, green-red & $0.580-0.680 \mu \mathrm{m}$ & Band 2 \\
\hline 3 & RBV & Visible, red-invisible IR & $0.690-0.830 \mu \mathrm{m}$ & Band 3 \\
\hline 1 & MSS & Visible green & $0.5-0.6 \mu \mathrm{m}$ & Band 4 \\
\hline 2 & MSS & Visible red & $0.6-0.7 \mu \mathrm{m}$ & Band 5 \\
\hline 3 & MSS & Invisible reflected IR & $0.7-0.8 \mu \mathrm{m}$ & Band 6 \\
\hline 4 & MSS & Invisible reflected IR & $0.8-1.1 \mu \mathrm{m}$ & Band 7 \\
\hline (5) & MSS & (Invisible thermal IR) & $(10.2-12.6 \mu \mathrm{m})$ & (Band 8$)^{1 /}$ \\
\hline
\end{tabular}

1/Landsat-C MSS, channel not on Landsats-1 and -2 . 


\section{ELECTROMAGNETIC SPECTRUM}
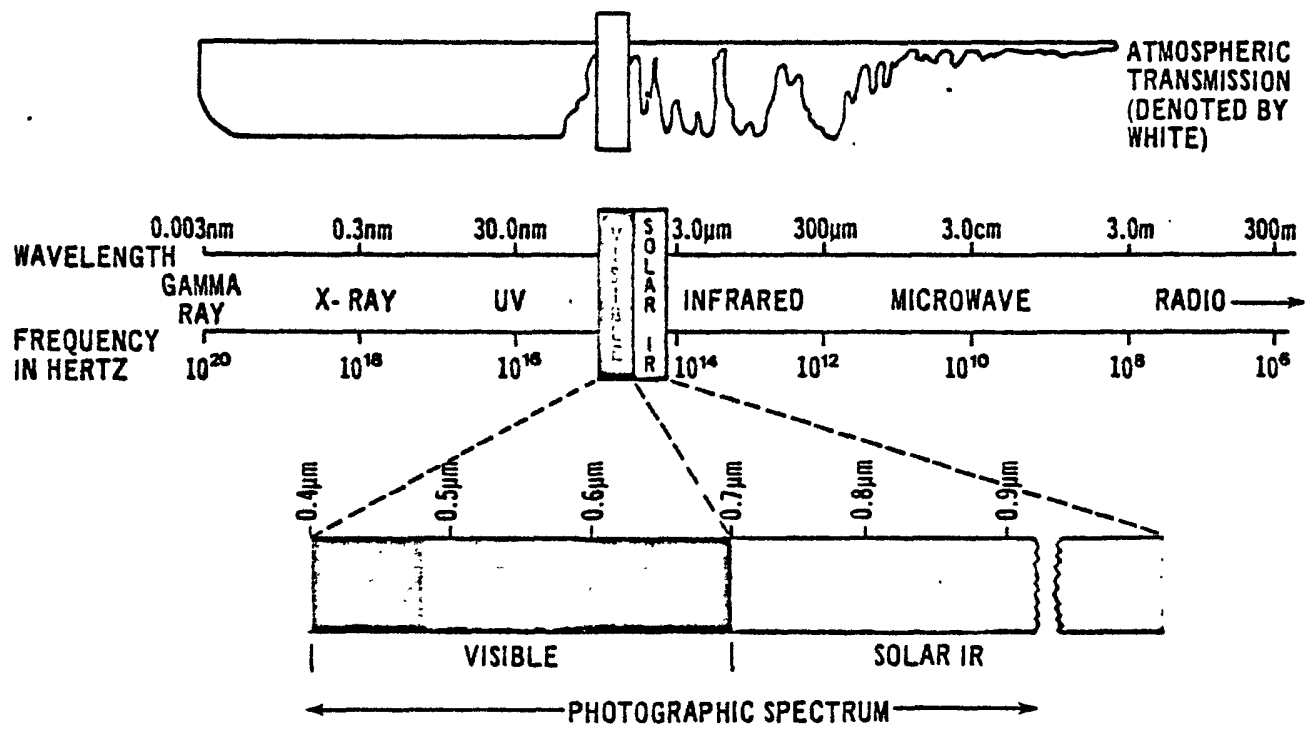

Figure 15: The electromagnetic spectrum with the visible range and reflected (solar infrared) range shown in detail. PAO Number: E-6326-35 
The Landsat Multispectral Scanner

Function of the Multispectral Scanner

A schematic drawing of the MSS is shown in figure 16. The MSS has an oscillating mirror that scans the Earth's surface from west to east. Radiation coming from the surface of the Earth and its atmosphere is reflected by the mirror into reflecting telescope optics, and focused on fiber optic bundles located in the focal plane of the telescope. The configuration and size of the fiber optic bundles determine instantaneous field of view (IFOV) of the sensor (fig. 17).

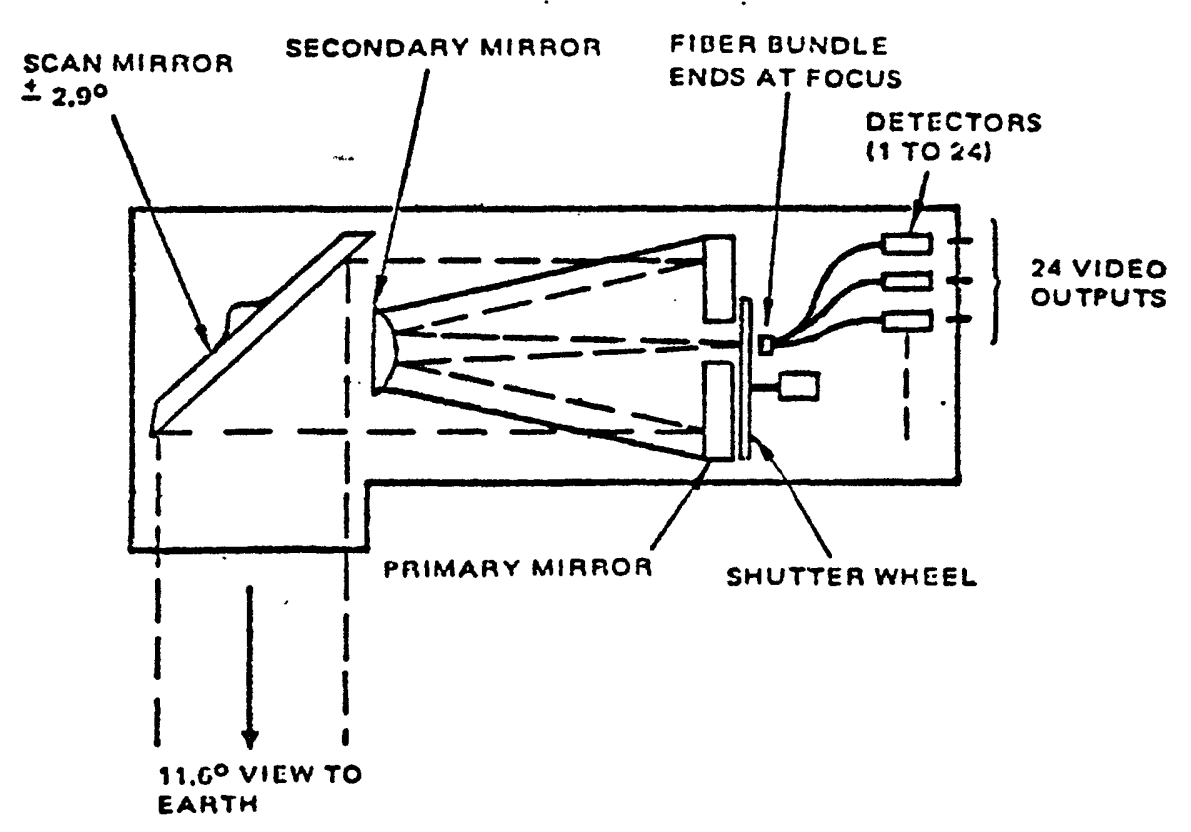

Figure 16: Schematic drawing of the MSS. From the final report on the MSS for ERTS, Hughes Aircraft. PAO Number: E-5845-35. 


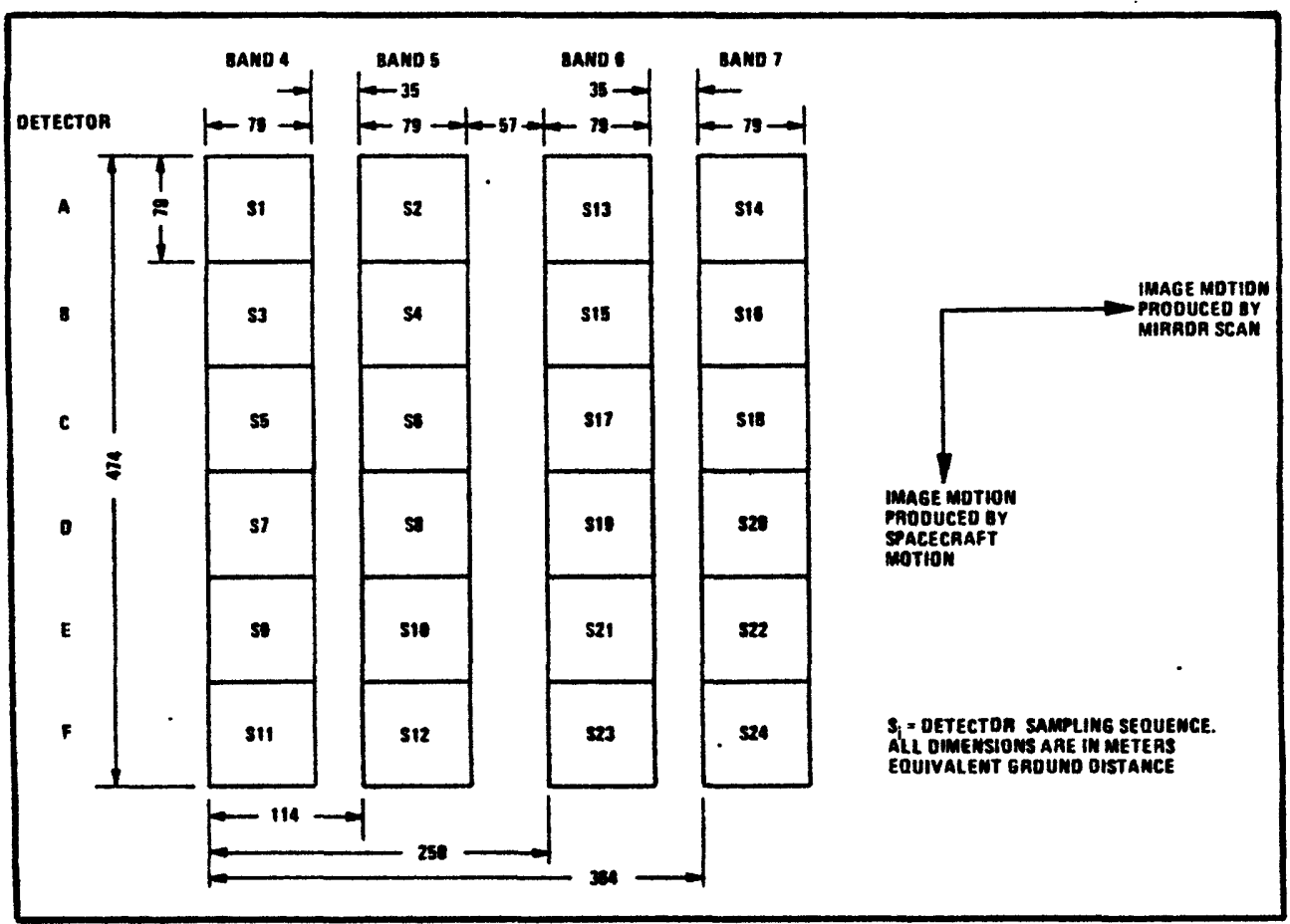

Figure 17: Geometry and ground dimensions for fiber optic bundles at the focal plane in the MSS telescope. From NASA Landsat Data Users Handbook.

Radiation is conducted by the fiber-optic light pipes to filters that permit only certain wavelengths of radiation to strike detectors. The voltage produced by each detector is related to the amount of radiation that reaches the detector. Each detector is capable of producing voltages from zero to five volts; however, only a 4-volt range is used. Two gain modes are used with the MSS bands 4 and 5 (figs. 18 and 19). The low-gain mode is used routinely over land surfaces, and the high-gain mode is sometimes used (on special request) over water surfaces. The gain is changed by ground command. The voltage produced by the detectors is an analog signal which is converted to values 


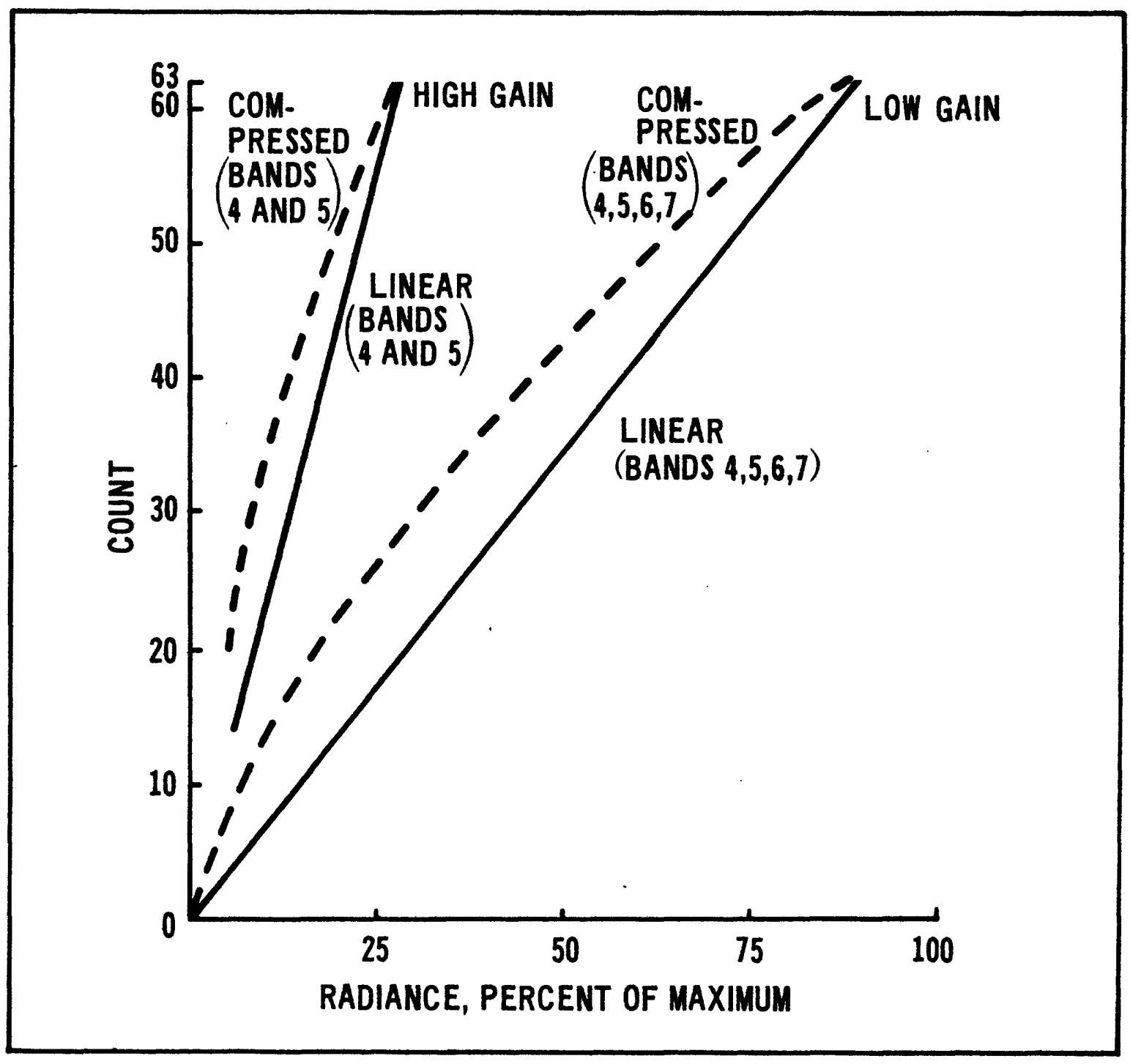

Figure 18: Relationship between maximum percent of radiance and digital count for MSS. NASA Landsat Data Users Handbook. 


\begin{tabular}{|c|c|c|}
\hline $\begin{array}{c}\text { MAXIMUM RADIANCE (BV }=63 \text { ) } \\
\text { (milliwatts/cm }\end{array} \mathrm{c}^{-}$SR) \\
\begin{tabular}{|c|c|c|}
\hline MSS BAND & LOW GAIN & HIGH GAIN \\
\hline 4 & 2.48 & 0.83 \\
5 & 2.00 & 0.67 \\
6 & 1.76 & - \\
7 & 4.60 & - \\
\hline
\end{tabular}
\end{tabular}

Figure 19: Maximum radiance for low and high-gain modes on the MSS. From NASA Land sat Data Users Handbook

(from $0-63$ ) by a multiplexer. The numbers represent brightness values (BV) related to the radiance of an area on the Earth's surface in one wavelength band (figs. 20 and 21 ).

The MSS mirror scans the Earth's surface from west to east in about 33 milliseconds (the mirror oscillates at a frequency of 13.62 hertz). Six lines of data are scanned at one time (fig. 22), and each line is about $185 \mathrm{~km}$ long on the ground. The satellite moves south during the scans, so lines are not exactly perpendicular to orbital path (fig. 23). During the retrace cycle of the mirror, a shutter blocks energy from the Earth, and detectors are exposed to internal light and sun calibration sources. Twenty-four detectors are 
used on the MSS (26 detectors on Landsat-C) to record the six lines of data in four wavelength bands.

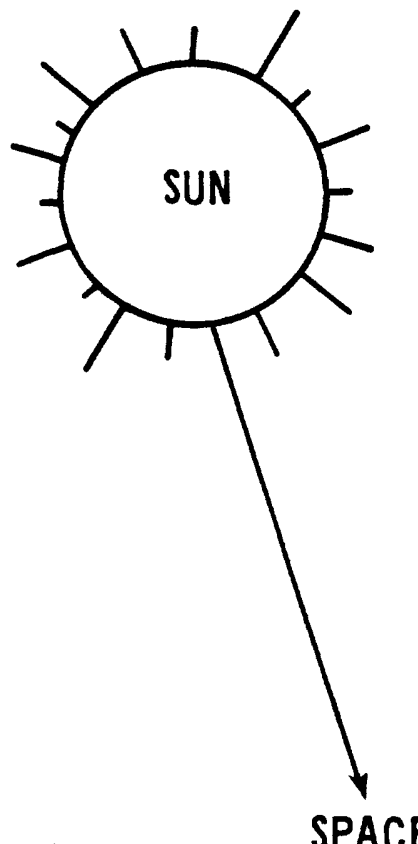

SATELLITE

DETECTION SYSTEM SPACE

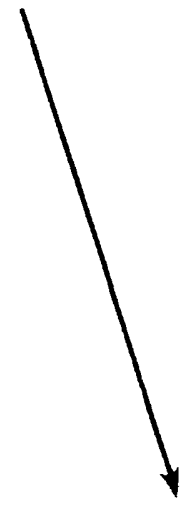

ATMOSPHERE ATMOSPHERE

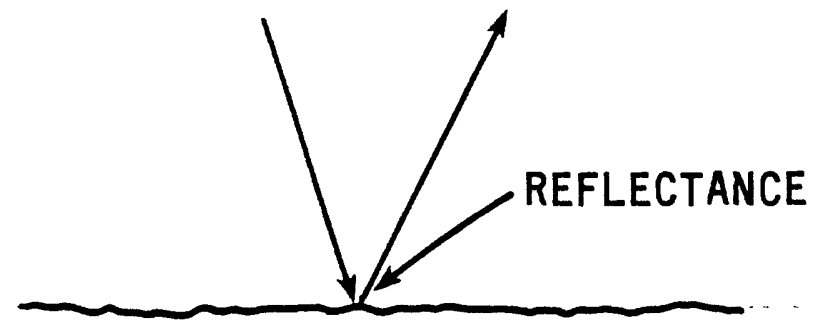

EARTH'S SURFACE<smiles>[CH]1CC1</smiles><smiles>[13CH]</smiles>

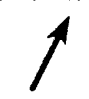

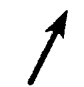

MSS DETECTOR VOLTAGE (0 - 4 VOLTS)

MSS DETECTOR RESPONSE

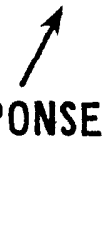

MSS FILTER TRANSMISSION<smiles>CCCC</smiles>

MSS FIBER OPTIC TRANSMISSION

MSS TELESCOPE TRANSMISSION

MSS MIRROR TRANSMISSION 


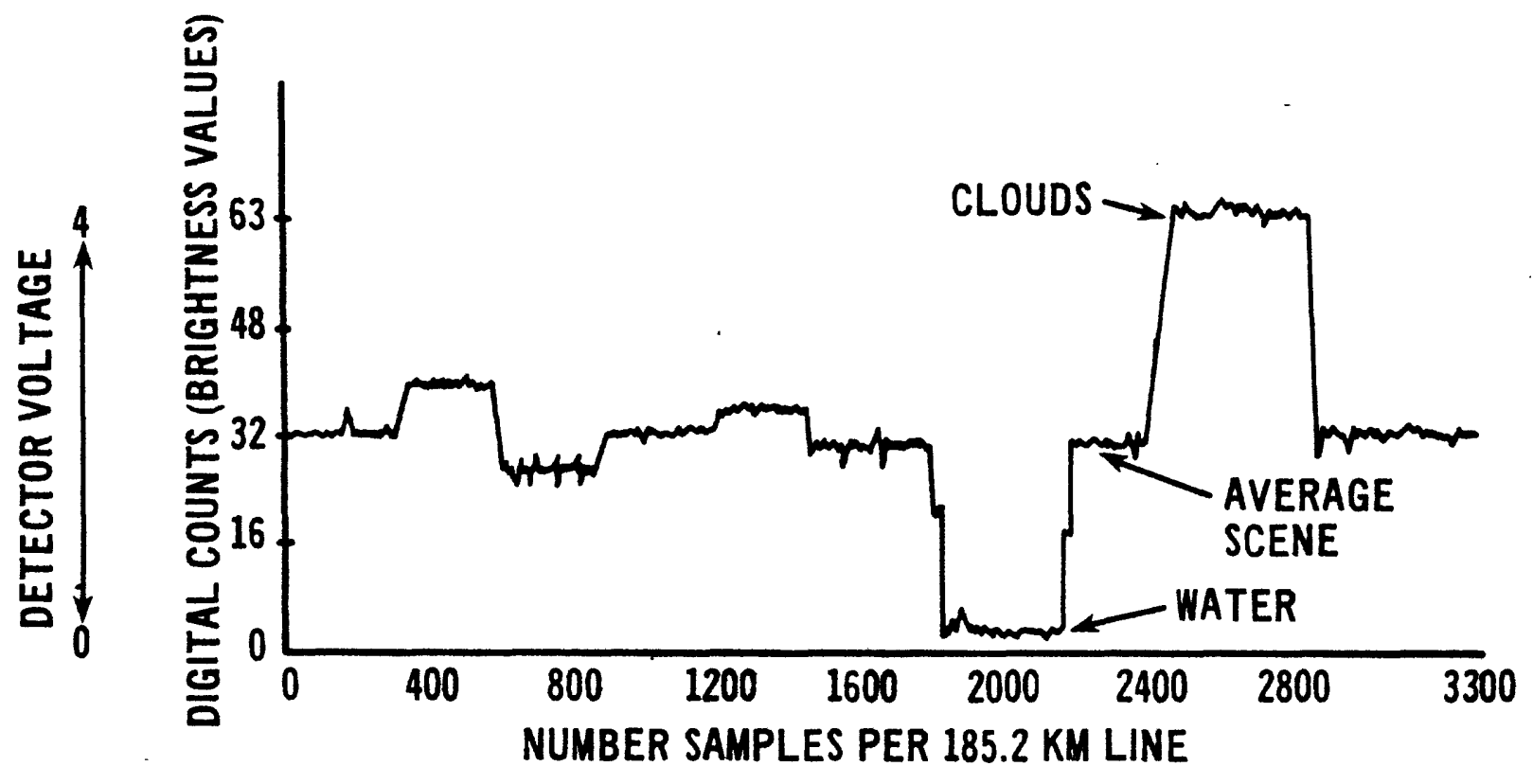

Figure 21: Relationship between voltage and digital count for a hypothetical scan line. From Ragland and Chavez, 1976. 


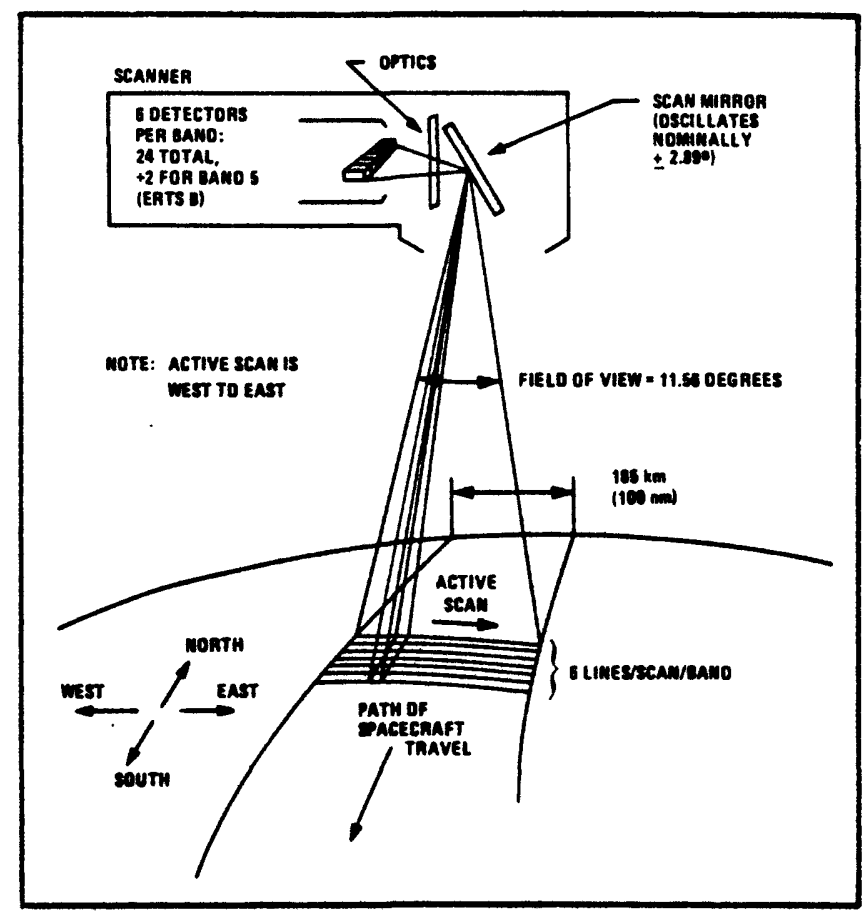

Figure 22: Scanning arrangement of the MSS. From NASA Landsat Data Users Handbook. PAO Number: E-6327-35.

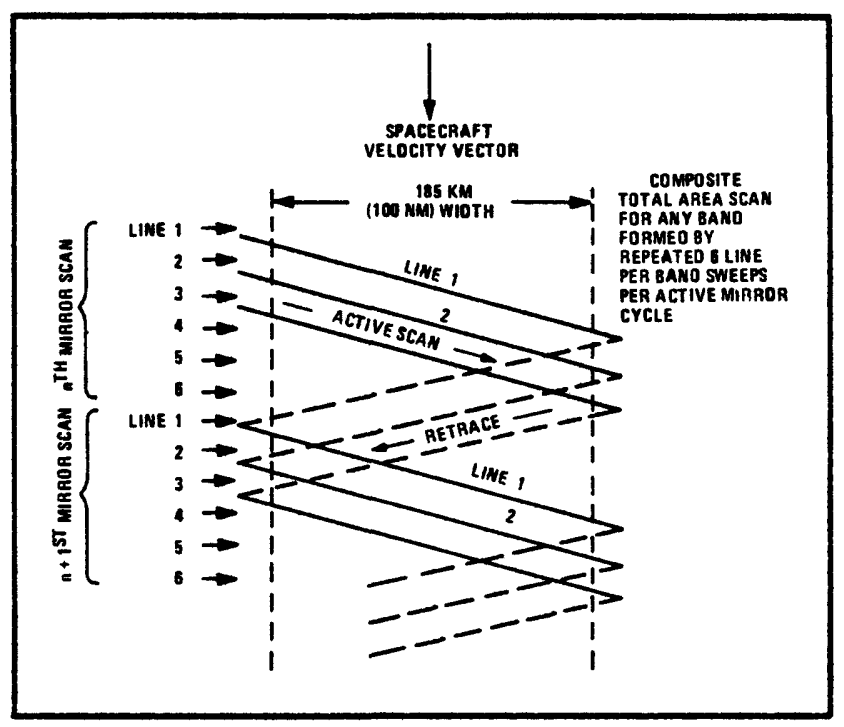

Figure 23: Scanning pattern of the MSS on the Earth's surface. NASA Landsat Data Users Handbook. PAO Number: E-6328-35. 
Formation of the MSS Picture Element

During each scan, the voltage produced by each detector is sampled every 9.95 microseconds. For one detector, approximately 3,300 samples are taken along a $185.2 \mathrm{~km}$ line (fig. 21). Thus, the instantaneous field of view (IFOV) of $79 \mathrm{~m}$ by $79 \mathrm{~m}$ moves about $56 \mathrm{~m}$ on the ground between each sample (fig. 24). The individual radiation measurements must be arranged on an image in a manner that preserves spatial relationships. Thus, the measurements are assigned dimensions of $56 \mathrm{~m}$ by $79 \mathrm{~m}$ so that geometric distortions are not introduced. The $56 \mathrm{~m}$ by $79 \mathrm{~m}$ area is called a Landsat picture element or pixel. Although the measurement of landscape brightness is made from a 6,241 square meter area, the data are formatted as if the measurement were made from a 4,424 square meter area (fig. 24). Note the overlap of the areas from which brightness measurements were made for adjacent pixels (fig. 24).

Detection of Ground Features With the MSS

The detection of ground features (fig. 24) is dependent upon relationships between the size of a feature and its brightness with respect to the brightness of the background against which the feature is imaged. The IFOV of the MSS integrates the brightness of all landscape cover. If a feature equal in size to the IFOV is to be detected, the feature must have a brightness of one over the background and the IFOV must exactly fit over the feature when the detector voltage is sampled (fig. 25). This is rarely the case, and usually the radiation from the IFOV is sampled when it covers only a part of the 

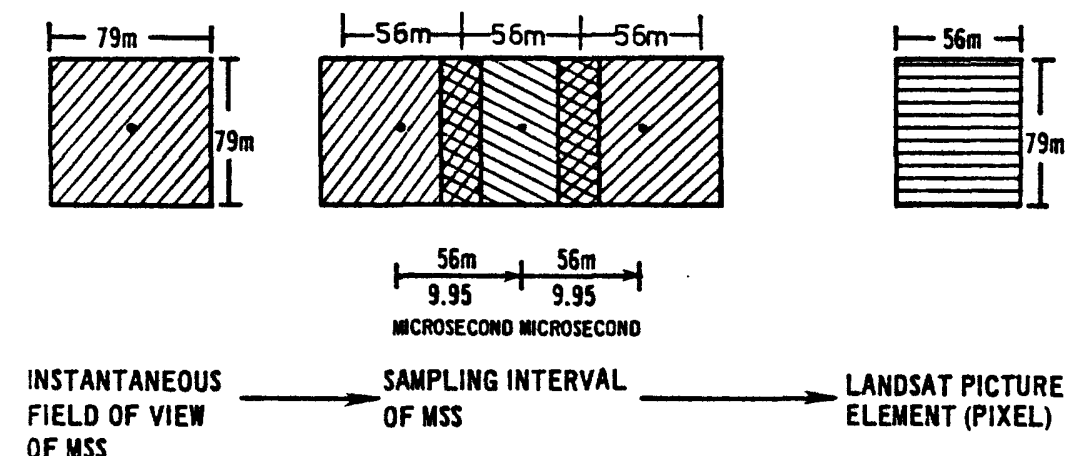

OF MSS

ENERGY MEASUREMENT

FORMATTED TO

- MADE FROM A 6241 SQUARE

METER AREA

Figure 24: Formation of the MSS picture element. PAO Number: E-6188-35.

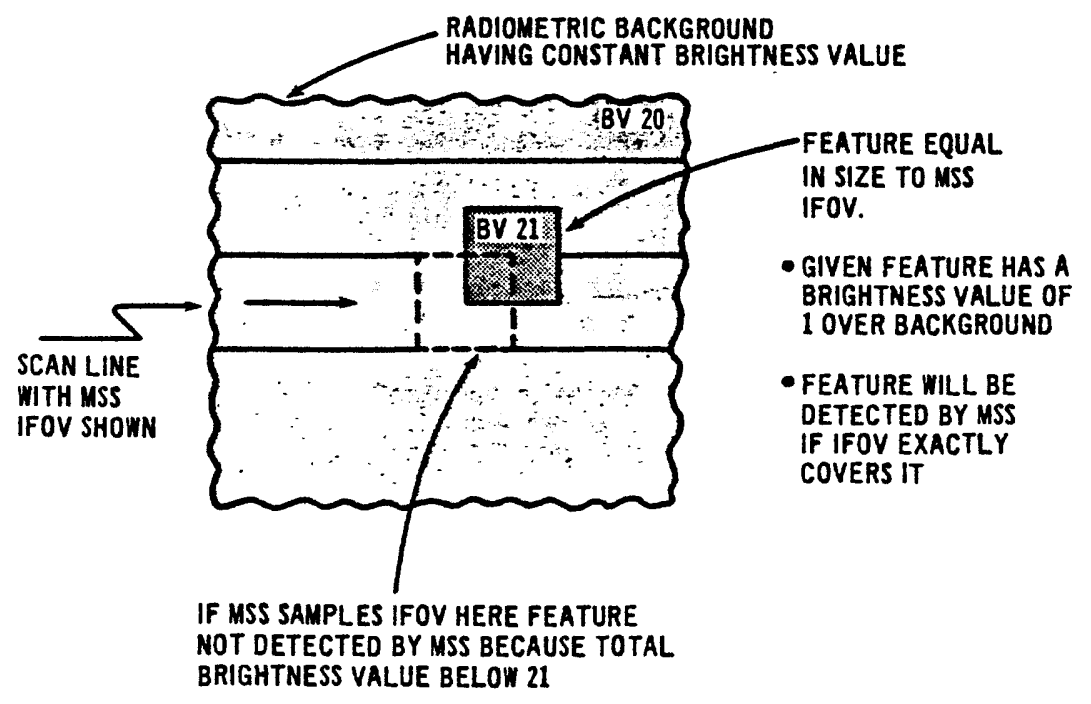

Figure 25: Detection of ground features with the MSS on Landsats-1 and -2 - Case 1. PAO Number: E-6189-35. 
feature (fig. 25). In this latter case the feature will not be detected. If the feature with a brightness of one over background is any smaller than the IFOV, it will not be detected even though the IFOV may completely cover the feature. Features which are smaller than the IFOV can be detected by the MSS if their brighness is sufficient to give a total brightness of one over background (fig. 26). If a feature smaller than the IFOV lies in the overlap area common to adjacent pixels, it is possible for the feature to influence the brightness of two picture elements if it has sufficient brightness (fig. 27). Depending upon the spectral characteristics of features and background against which they are imaged, features detected in one spectral band may not be detected in another spectral band.

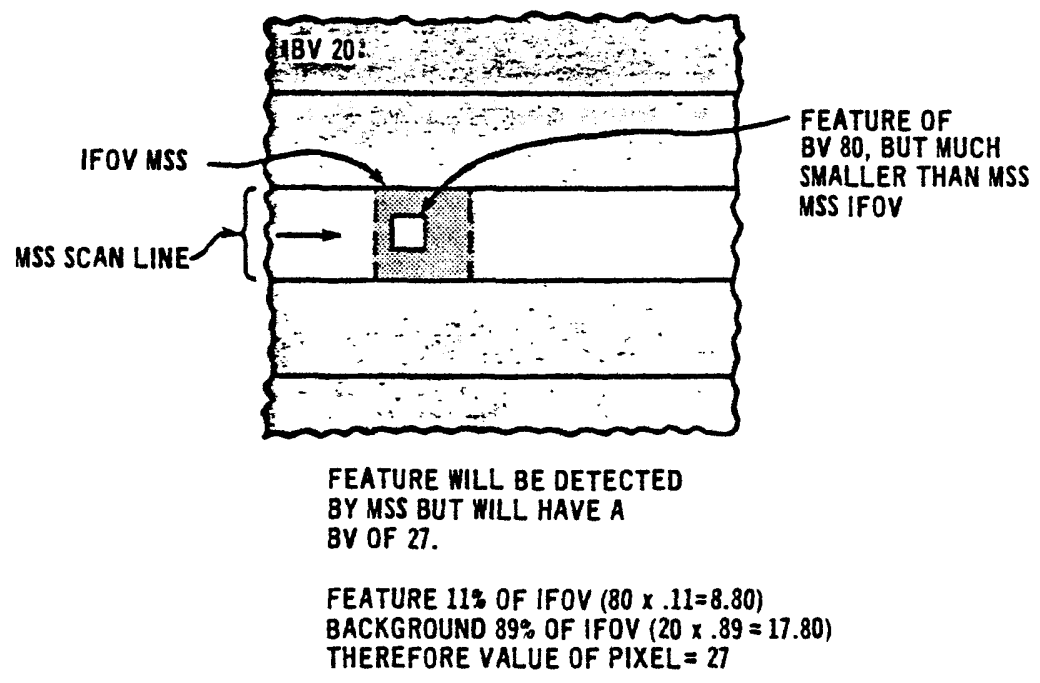

Figure 26: Detection of ground features by the MSS on Landsat - Case 2. PAO Number: E-6190-35. 


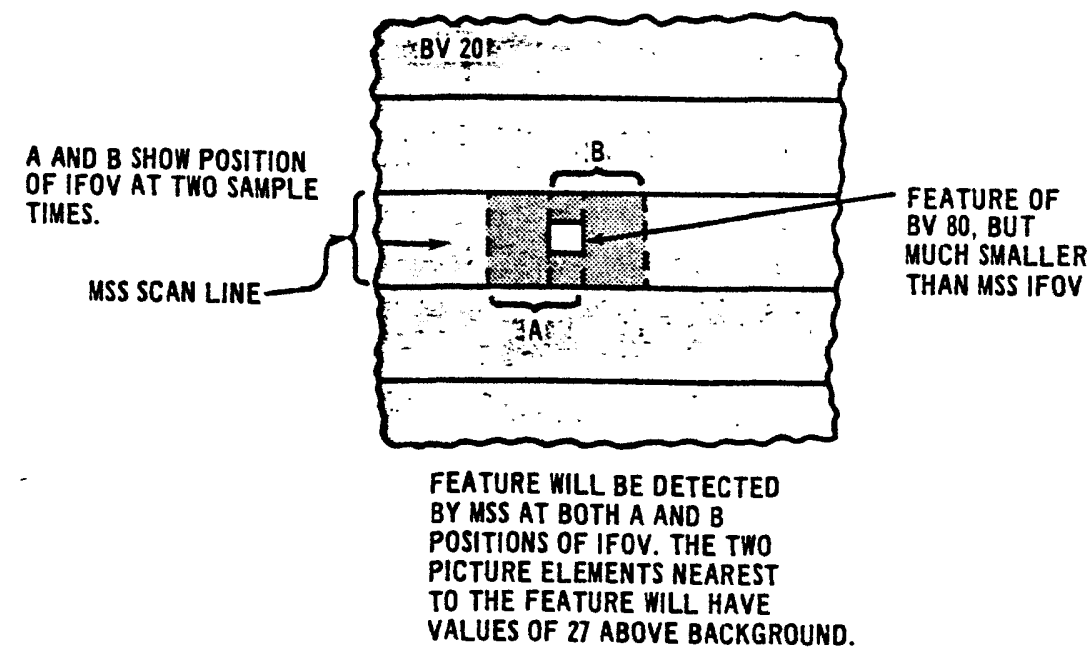

Figure 27: Detection of ground features by the MSS on Landsat - Case 3. PAO Number: E-6191-35.

A spatial array of picture elements and their values for one Landsat band is shown in figure 28. Two roads with brightness values of 80 , cut diagonally across a background that has a brightness value of 20. If all the pixels influenced by brightness from roads were shaded, the patterns would no longer be straight and continuous, but would appear as rectangular segments. No pixels in the array have a brightness value of 80 because the roads are smaller than the IFOV.

Integration of Ground Spectral Response

If red sandstone and green vegetation were present in equal amounts in an area scanned by the MSS, the resulting spectral signature would not resemble the signature for the vegetation or the 


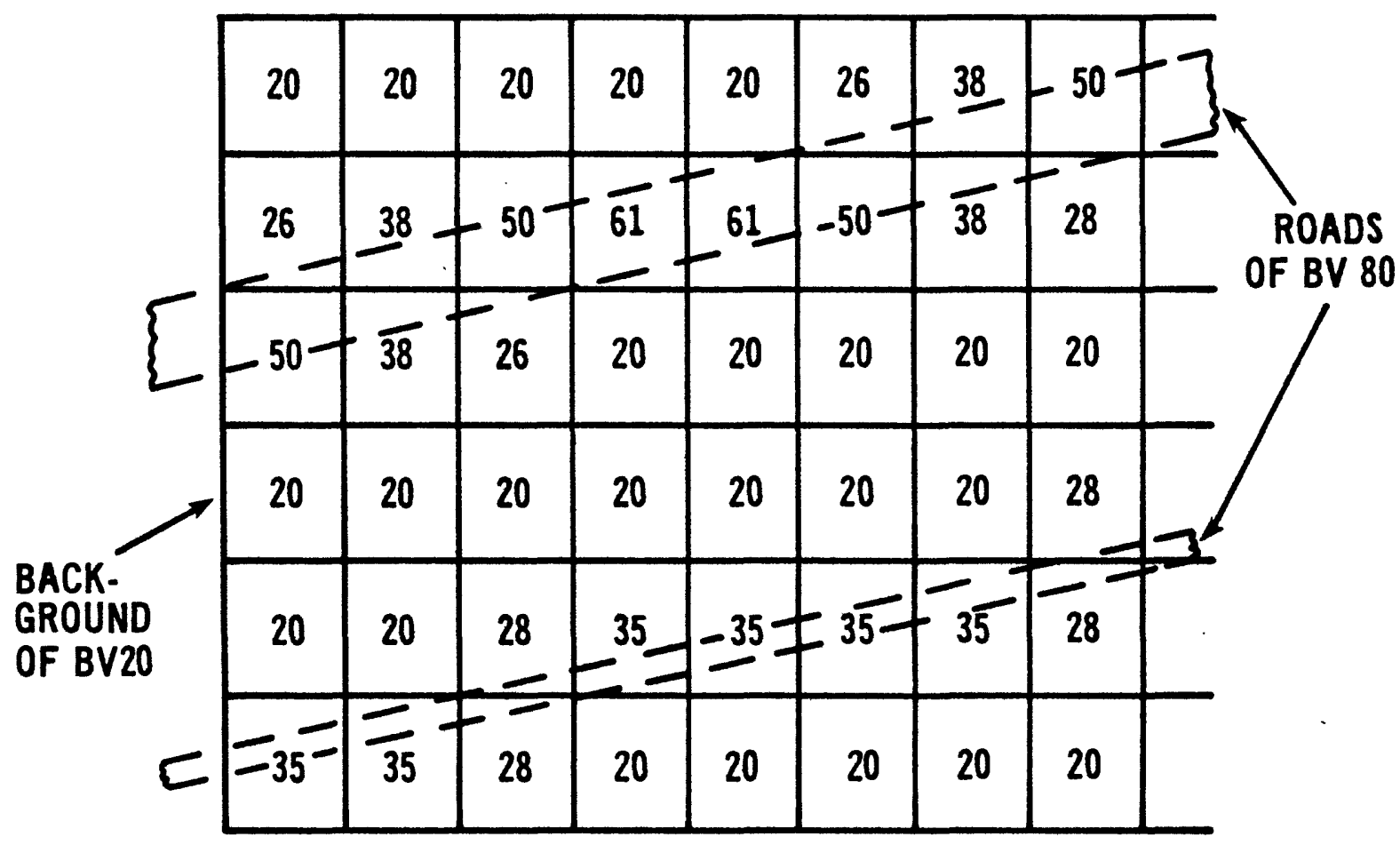

Figure 28: Spatial array of pixels and brightness values (BV) from a portion of one Landsat band. PAO Number: E-6329-35

signature for red sandstone (fig. 29). The combined spectral

signature is an average of the spectral signatures for the two cover types in the IFOV. The resultant spectral signature shown in figure 29 does not account for the effects of the atmosphere between the ground and the satellite.

The area sampled by the Landsat MSS is about the size of a football field, and thus, there is always an excellent probability that some combination of vegetation, soils, unconsolidated material, and cultural features will influence the detected spectral characteristics of rock units. One of the most important considerations in making comparisons between ground-based observations of geologic materials (alteration zones, 1ithology, etc.) and Landsat data is an understanding 


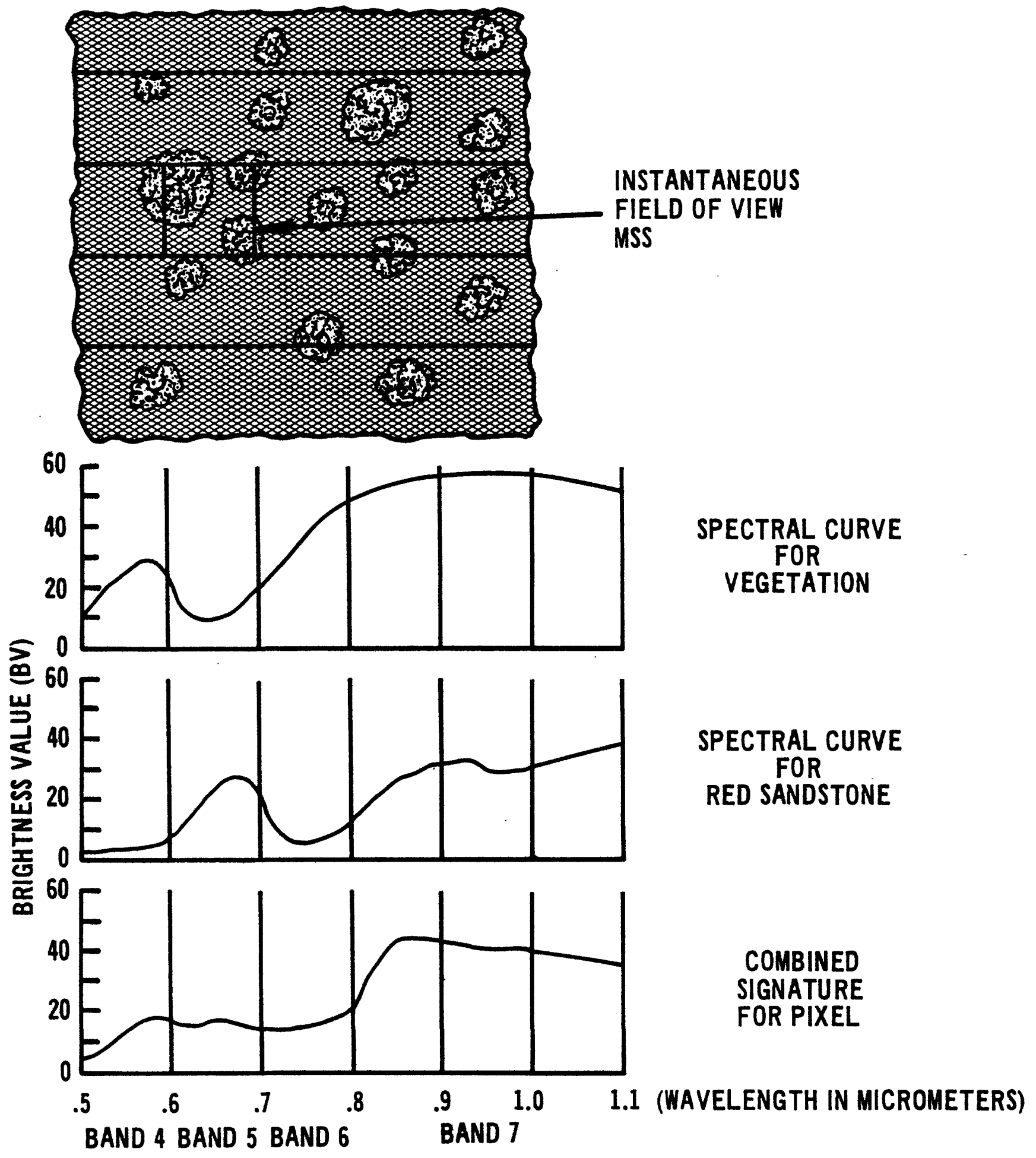

Figure 29: Integration of spectral response within the Landsat MSS

IFOV. Atmospheric effects not considered. PAO Number: E-6192-35. 
of cover conditions in the area being sampled by the MSS. The fact that the MSS integrates spectral characteristics of the landscape from large areas, instead of making discrete spectral measurements from individual cover types might appear to be a serious limitation of Landsat data. In some situations and applications, the size of the IFOV of the MSS is a serious problem. However, some cover conditions develop in response to the geology, and often the combination of soils, soil moisture, vegetation, etc., produce a characteristic spectral signature for an area which might be otherwise overlooked by a groundbased scientist who gathers data only on individual cover types such as 1ithology.

Effects of the Atmosphere on Landscape Spectral Brightness Solar radiation is largely unaffected as it travels through space, but it is selectively scattered and absorbed by the Earth's atmosphere (fig. 30). The atmosphere scatters green (band 4) wavelengths of solar radiation four times more than infrared (band 6) radiation of longer wavelength (figs. 31 and 32). Atmospheric absorption which is largely a function of water vapor and other gases in the atmosphere, mostly affects radiation of wavelengths longer than 0.8 micrometer (band 7) (figs. 33 and 34). Atmospheric scattering adds a brightness while atmospheric absorption subtracts a brightness from landscape spectral brightness.

The combination of integration of spectral brightness from different cover types (fig. 35) and the effects of the atmosphere on spectral brightness (figs. 36 and 37) introduces problems for direct 
SCATTERING

- AFFECTS SHORTER WAVELENGTHS MOST

- BAND 4 AFFECTED 4 TIMES MORE THAN BAND 7

- REDUCES LANDSCAPE REFLECTANCE AND ADDS ATMOSPHERIC BRIGHTNESS TO DATA - NET RESULT, A LOSS IN SCENE CONTRAST.

ABSORPTION

- LARGELY A FUNCTION OF WATER VAPOR

- AFFECTS BAND 7 MOST

- REDUCES LANDSCAPE REFLECTANCE

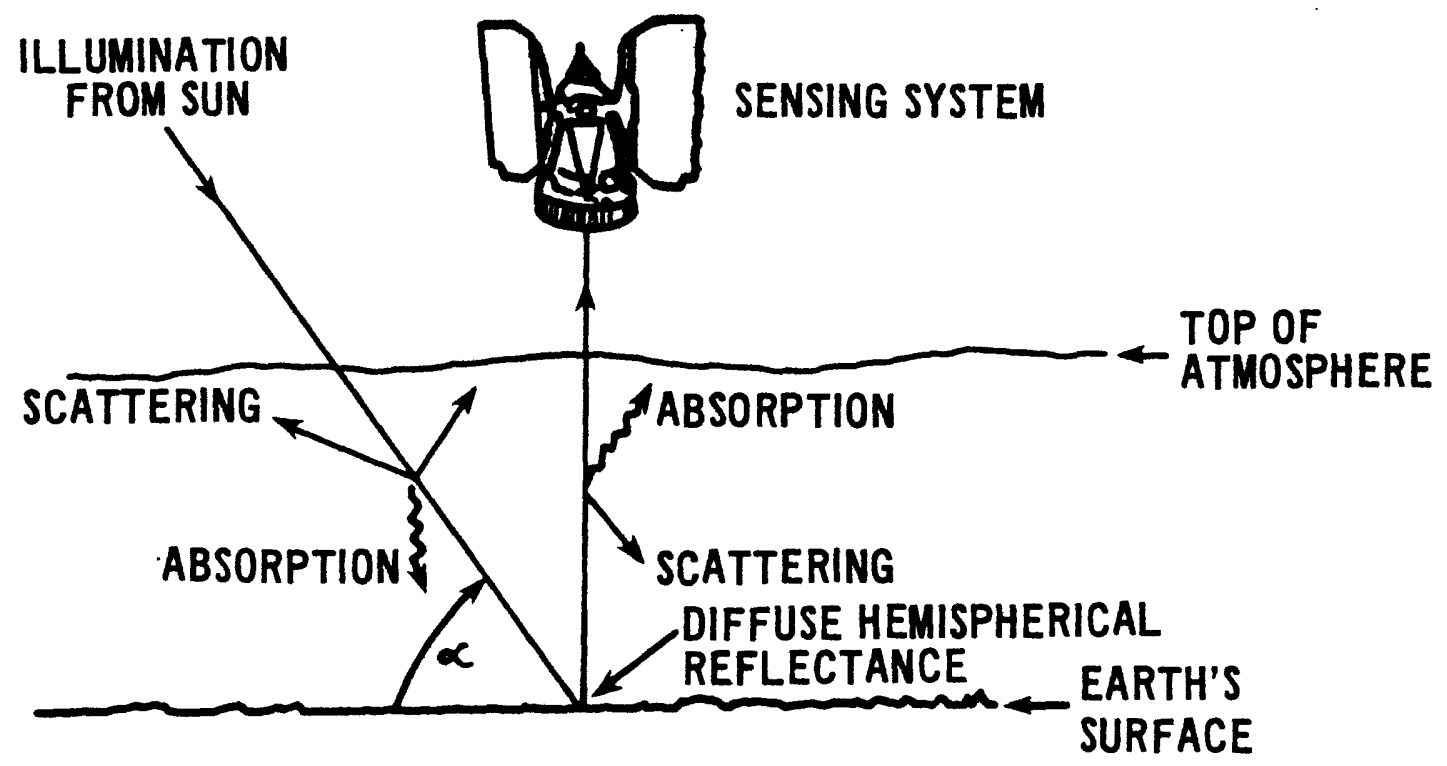

Figure 30: Atmospheric effects on the energy path between the sun and Landsat satellite. PAO Number: E-6183-35. 


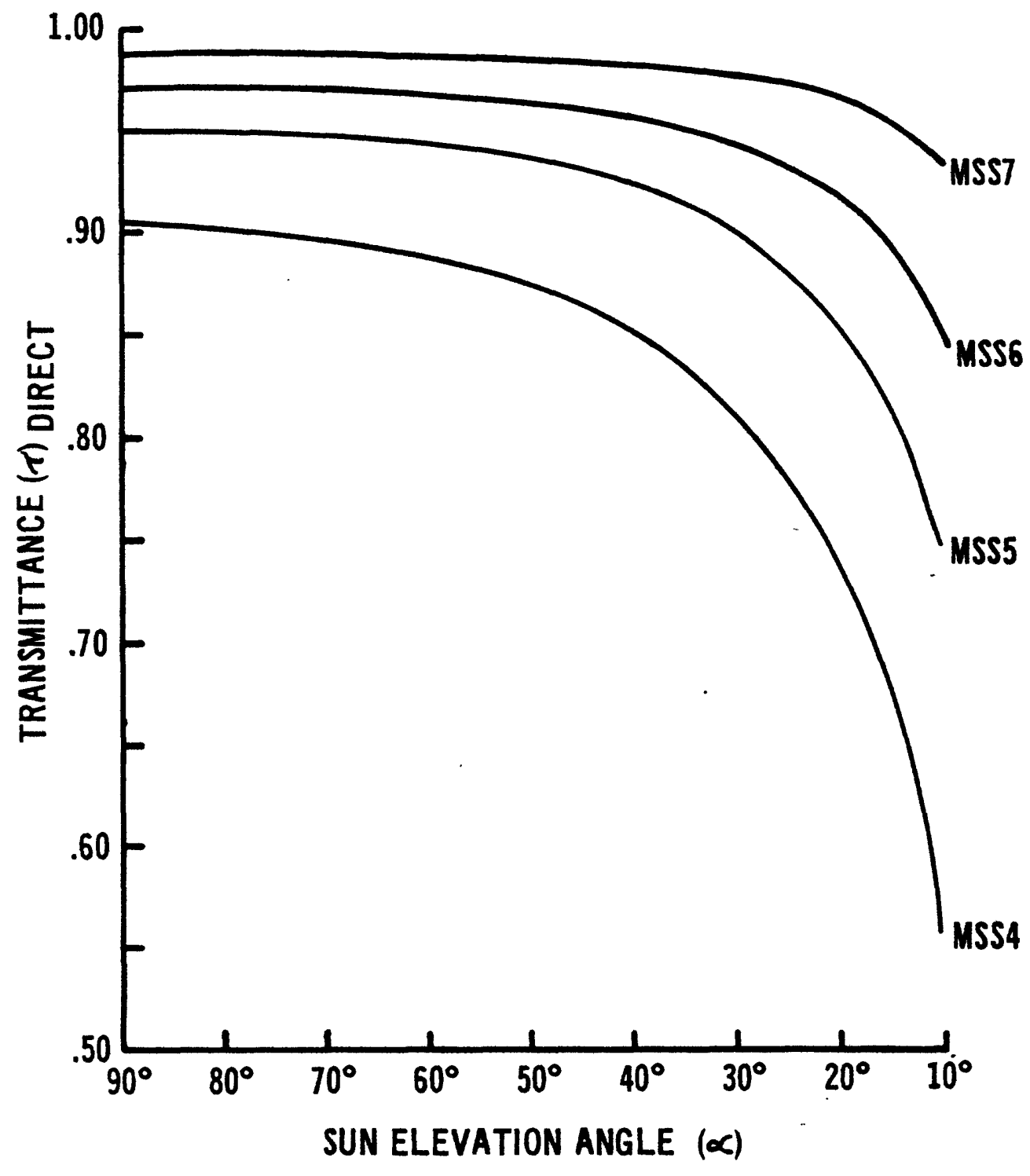

Figure 31: Effect of molecular scattering (Rayleigh) and sun angle on radiation transmitted to Earth's surface. Data from Trautwein, personal communication. 


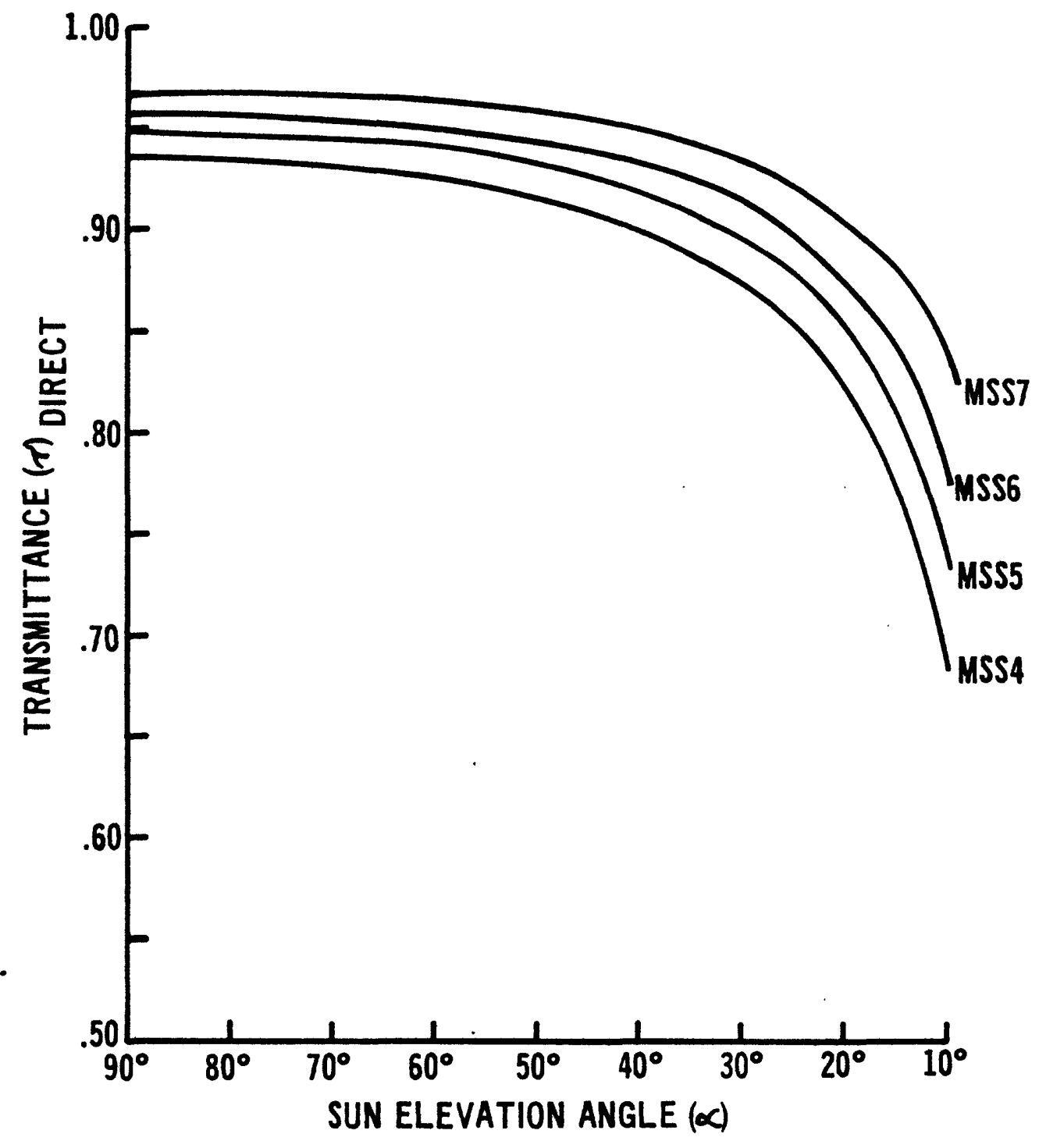

Figure 32: Effect of aerosol scattering (Mie) and Sun angle on radiation transmitted to Earth's surface. Data from Trautwein, personal communication. 


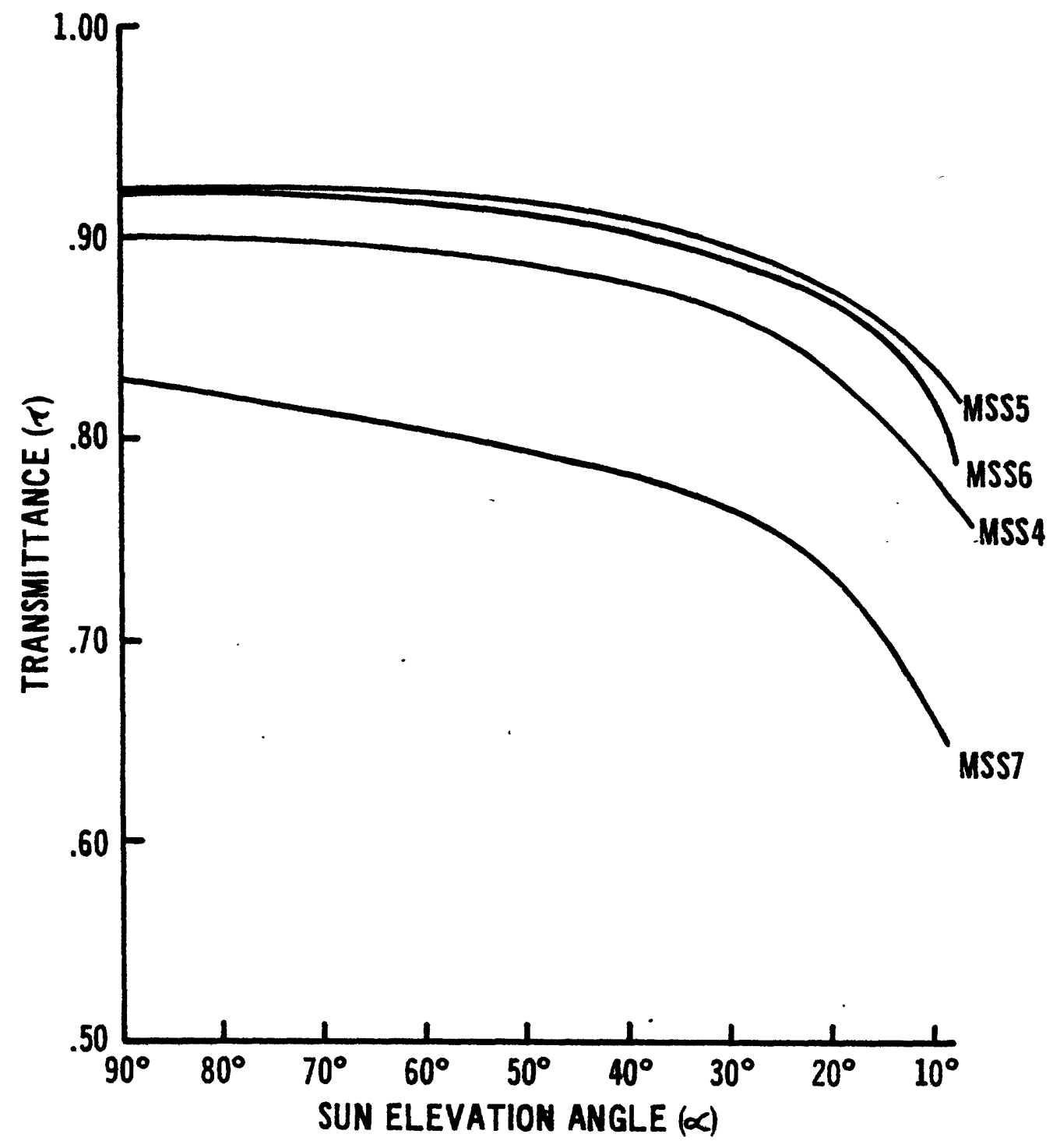

Figure 33: Effect of water vapor absorption and Sun angle on solar radiation transmitted through the atmosphere to the Earth's surface ( $1 \mathrm{~cm}$ precipitable water). Data from Trautwein, personal communication. 


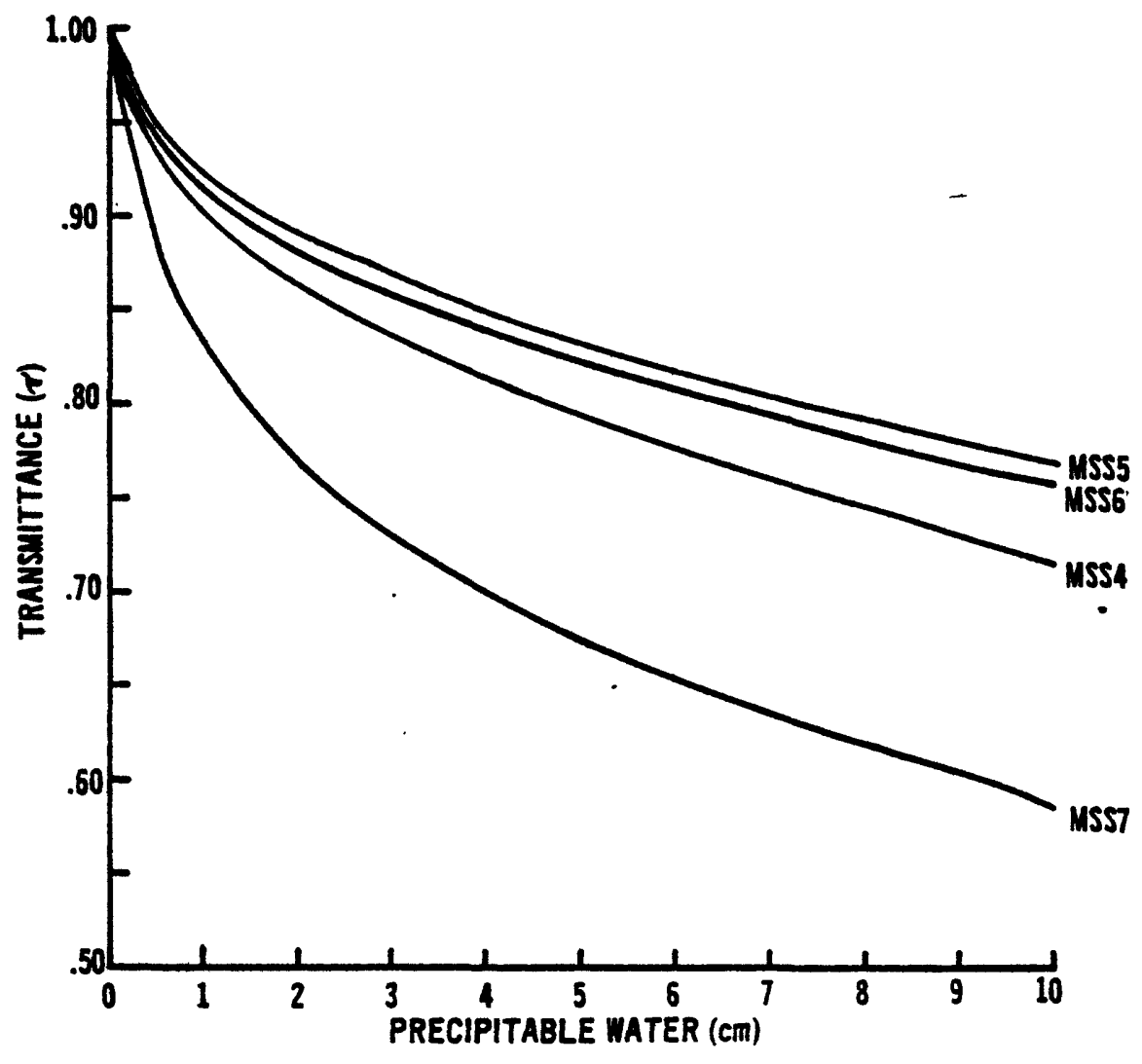

Figure 34: Effect of water vapor absorption on transmittance of Landscape brightness from Earth's surface to Landsat. Data from Trautwein, personal communication.

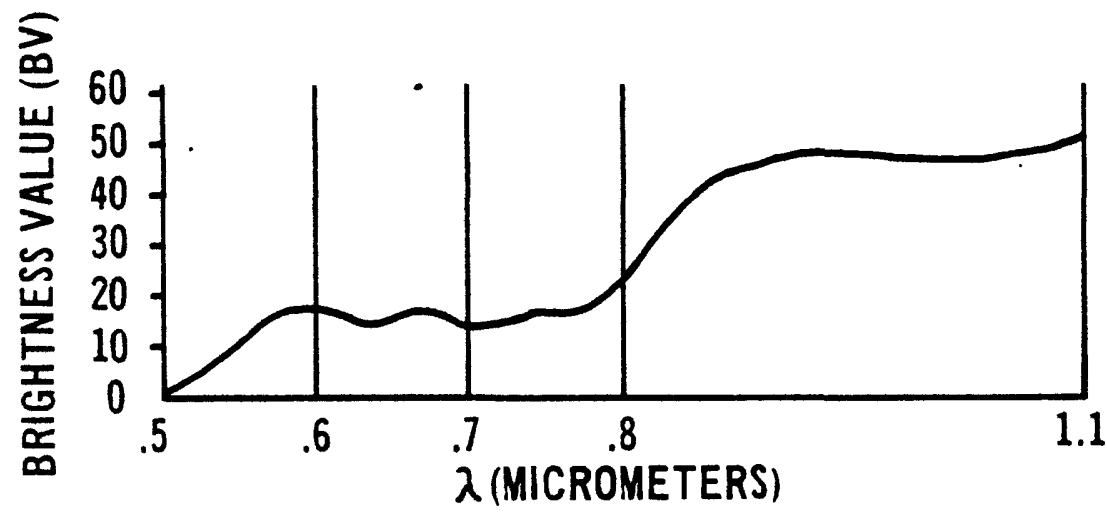

Figure 35: Integrated spectral brightness for a landscape covered with red sandstone and green vegetation, assuming no atmosphere and equal proportions of the cover types, PAO Number: E-6193-35. 


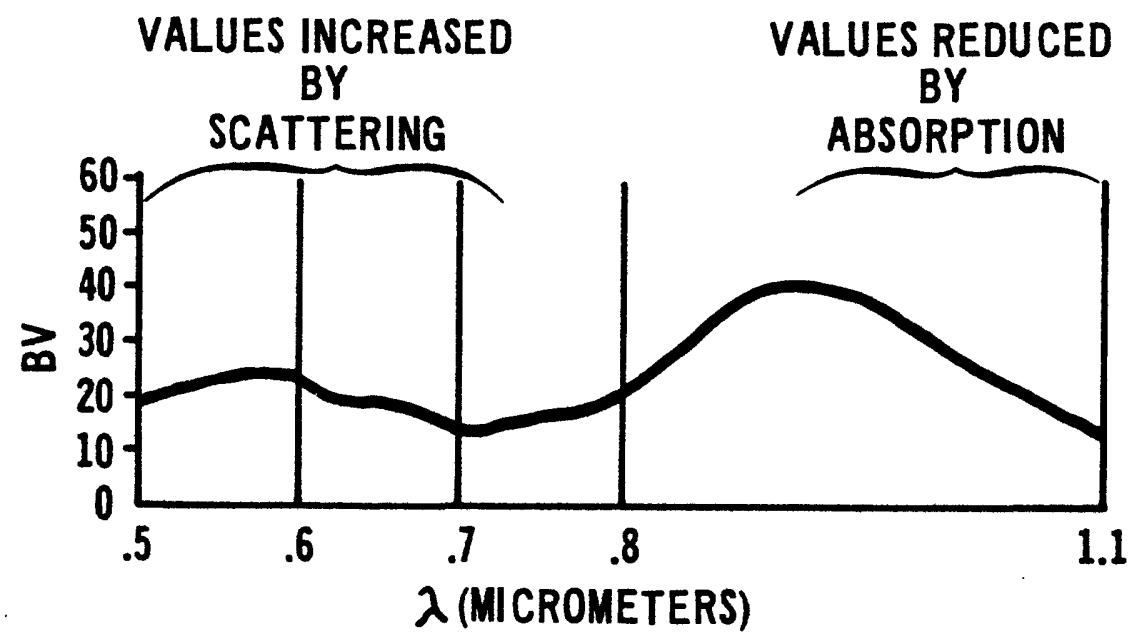

Figure 36: Landscape brightness for an IFOV area of the MSS that is composed of equal amounts of red sandstone and green vegetation, after radiation has passed through atmosphere. PAO Number: E-6193-35.

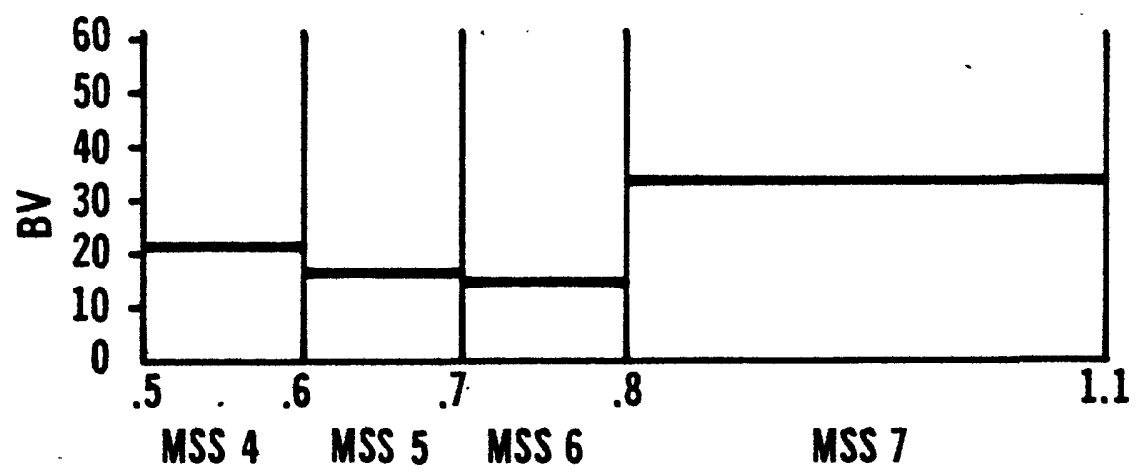

Figure 37: MSS Spectral record of landscape brightness in four wavelength bands for MSS IFOV containing equal amounts of red sandstone and green vegetation. PAO Number: E-6193-35. 
comparisons between ground-based measurements of spectral response from individual cover types, and measurements of spectral brightness by the MSS. Adjustments for atmospheric scattering are routinely applied to Landsat data, but corrections for atmospheric absorption are difficult. (see Taranik, in press).

Tape Recording of Landsat Data Onboard Satellite

Two wide-band video recorders, each having a 30-minute recording capability of 15 megabites of digital data per second, are part of the payload of Landsats -1 and -2 . Data are recorded on 2 -inch wide tape by four recording heads that are mounted on a rotating wheel, which is aligned at right angles to the direction of movement of the tape. The tape recorders may be turned on either by direct ground command, or they can be programmed to record data when out of range of ground telemetry. Only one recorder remains functional on Landsat-2 (fig. 38).

\section{LANDSAT-1 AND -2 DATA HANDLING}

As multispectral data are collected by the MSS, they are either relayed in real time to a ground station or are recorded for playback in the future. Landsat MSS data are transmitted to the Earth in a serial stream at 15 megabits per second, using a S-band frequency of $2265.5 \mathrm{MHz}$. NASA maintains three data reception facilities in the United States for Landsat data; Goldstone, in the Mohave Desert of California; Gillmore Creek, Fairbanks, Alaska; and Goddard Space Flight Center in Greenbelt, Maryland (fig. 39). There are foreign receiving sites in Canada (2), Brazil, Italy, and Iran (Pakistan was used as a site until Iran became 


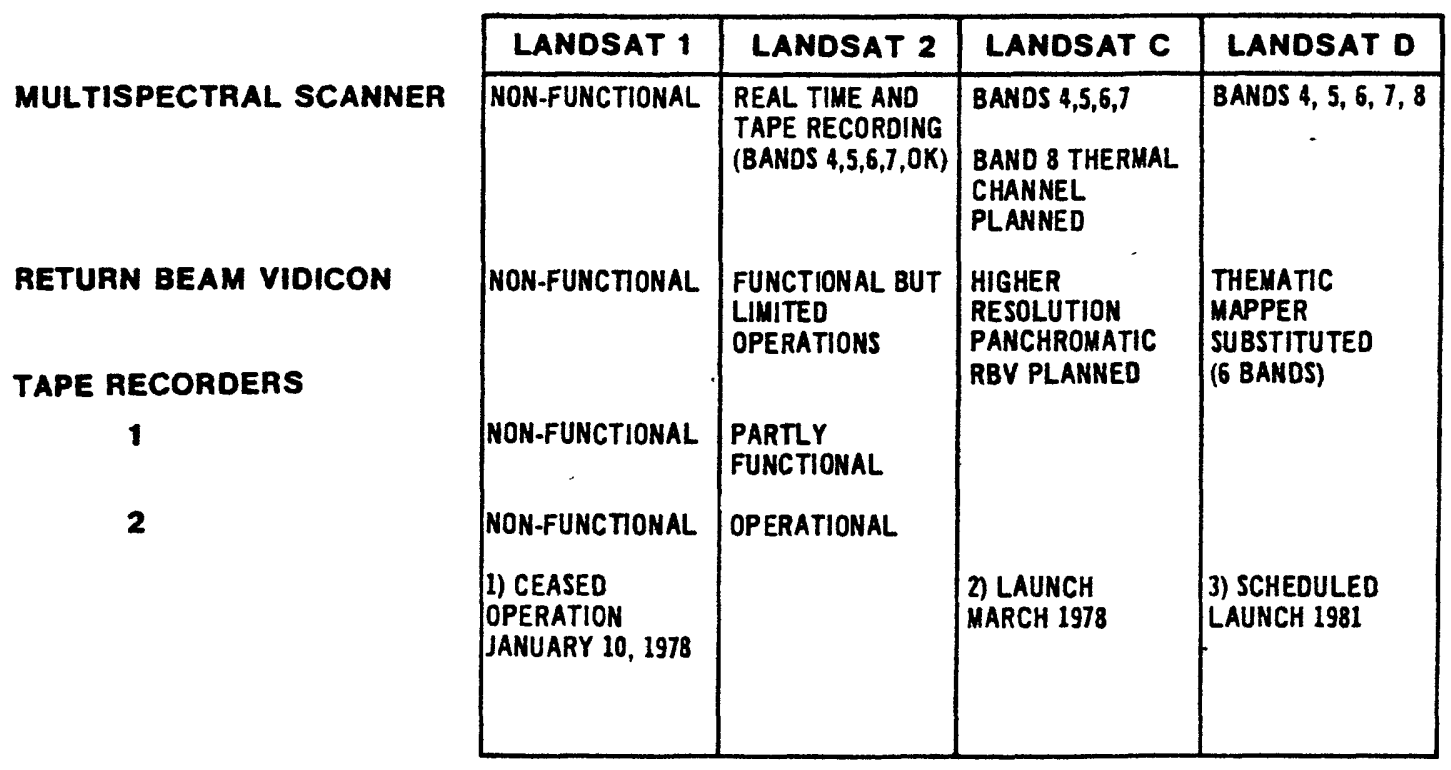

Figure 38: Landsat data collection status, January, 1978. 


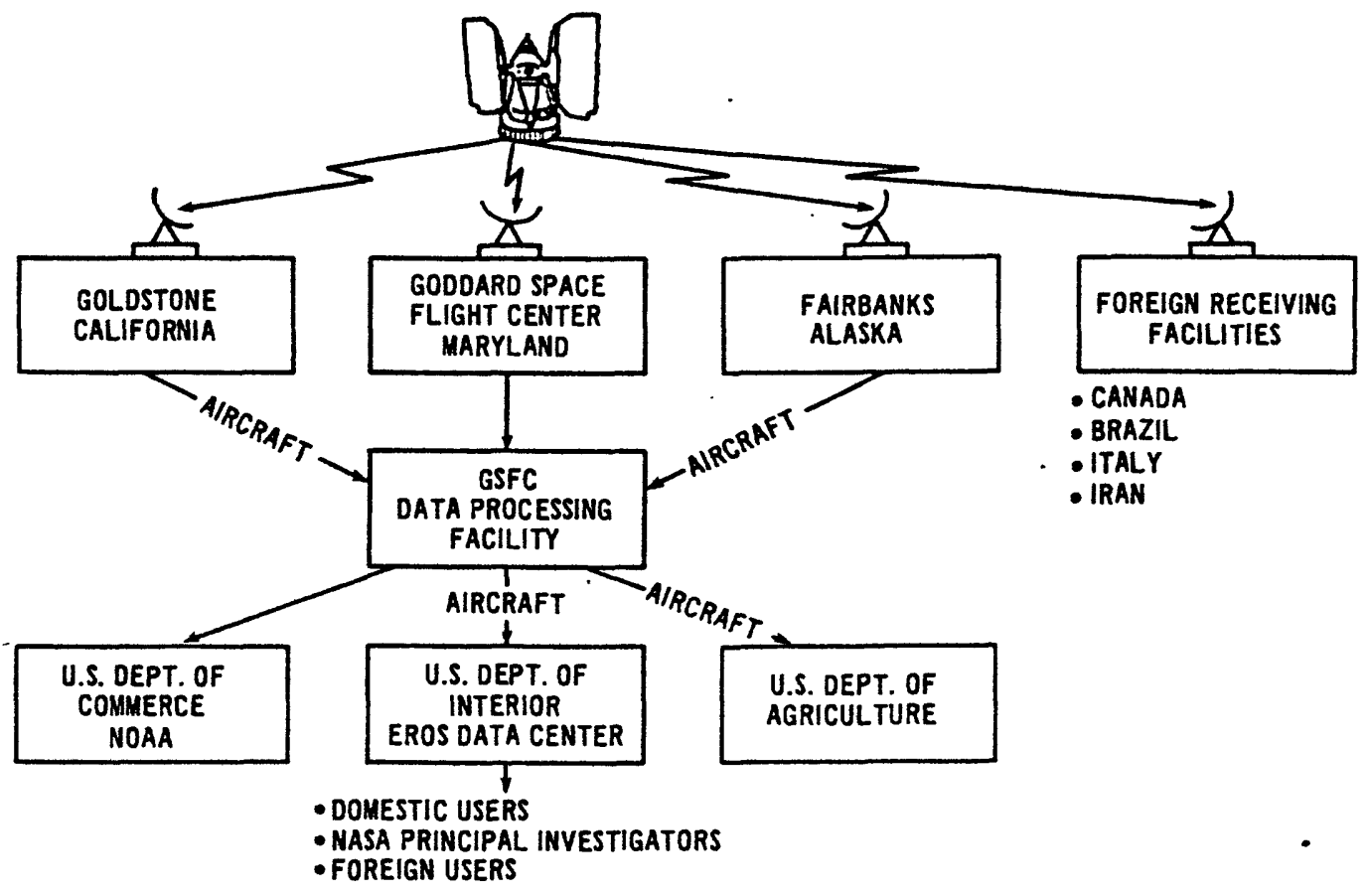

Figure 39: Landsat-1 and -2 data flow. PAO Number: E-6204-35 
operationa1). Negotiations are underway for Asian, other South American, and African stations as well (fig. 40).

U.S.A. (3)

CANADA (2)

BRAZIL

ITALY

IRAN (PAKISTAN)

REMAINDER OF EARTH

\begin{tabular}{|l|l|l|c|}
\hline LANDSAT 1 & LANDSAT 2 & LANDSAT C & LANDSAT D \\
\hline & REAL TIME & LAUNCH 1978 & LAUNCH 1981 \\
& $\begin{array}{l}\text { REAL TIME, USING } \\
\text { CLOUD COVER } \\
\text { REAL TIME,SPECIAL } \\
\text { SATELUUTE } \\
\text { NOT } \\
\text { RUNCTIONAL } \\
\text { REQUEST ONLY } \\
\text { REAL TIME,SPECIAL } \\
\text { REQUEST } \\
\text { REAL TIME,SPECIAL } \\
\text { REQUEST }\end{array}$ & & \\
& $\begin{array}{l}\text { TAPE RECORDER } \\
\text { PER SPECIAL } \\
\text { REQUIREMENTS }\end{array}$ & & \\
\hline
\end{tabular}

OTHER PLANNED RECEIVING STATIONS:

CHILE (AGREEMENT SIGNED)

ARGENTINA (NEGOTIATION)

AUSTRALIA (DISCUSSED)

JAPAN (DISCUSSED)

USSR (DISCUSSED)

Figure 40: Landsat System mode of operations. 
Receiving site equipment arranges multiplexed data into individual data channels, one channel for each detector on the MSS. A preamble line-start code and a line-length code are added to each channel, and the data are recorded in parallel lines on video tape. The wide band video recordings produced by the receiving stations at remote sites in the United States are shipped by air to Goddard Space Flight Center (fig. 39).

The operations control center at GSFC produces an image annotation tape that has mission parameters necessary for annotation and correction of the video tape data from the receiving stations. The NASA Image Processing Facility at GSFC uses the station video tape and the annotation tape to produce $70 \mathrm{~mm}$ master images from all data collected by the MSS (fig. 41). Computer compatible tapes (CCT's) are produced on user request.

Film recording at GSFC is done on an electron beam recorder (EBR) that produces archival positive images on $70 \mathrm{~mm}$ wide film (fig. 42). The electron beam recorder functions much like a cathode ray tube in an oscilliscope. The intensity of a beam of electrons is modulated as the beam is focused and aligned by deflection coils. Film recording is done so film transmission on a positive image is linear with sensor brightness value (digital count). The second generation negative $(\mathrm{N}-2)$ sent to U.S. Government distribution centers has a density range of $0.4 \mathrm{D}$ to $2.4 \mathrm{D}$ and a gamma of 1 .

The EROS Data Center prints the $\mathrm{N}-2$ 's to third generation, $70 \mathrm{~mm}$ positives ( $\left.\mathrm{P}-\mathrm{3}^{\prime} \mathrm{S}\right)$, with a density range which is more easily used in 


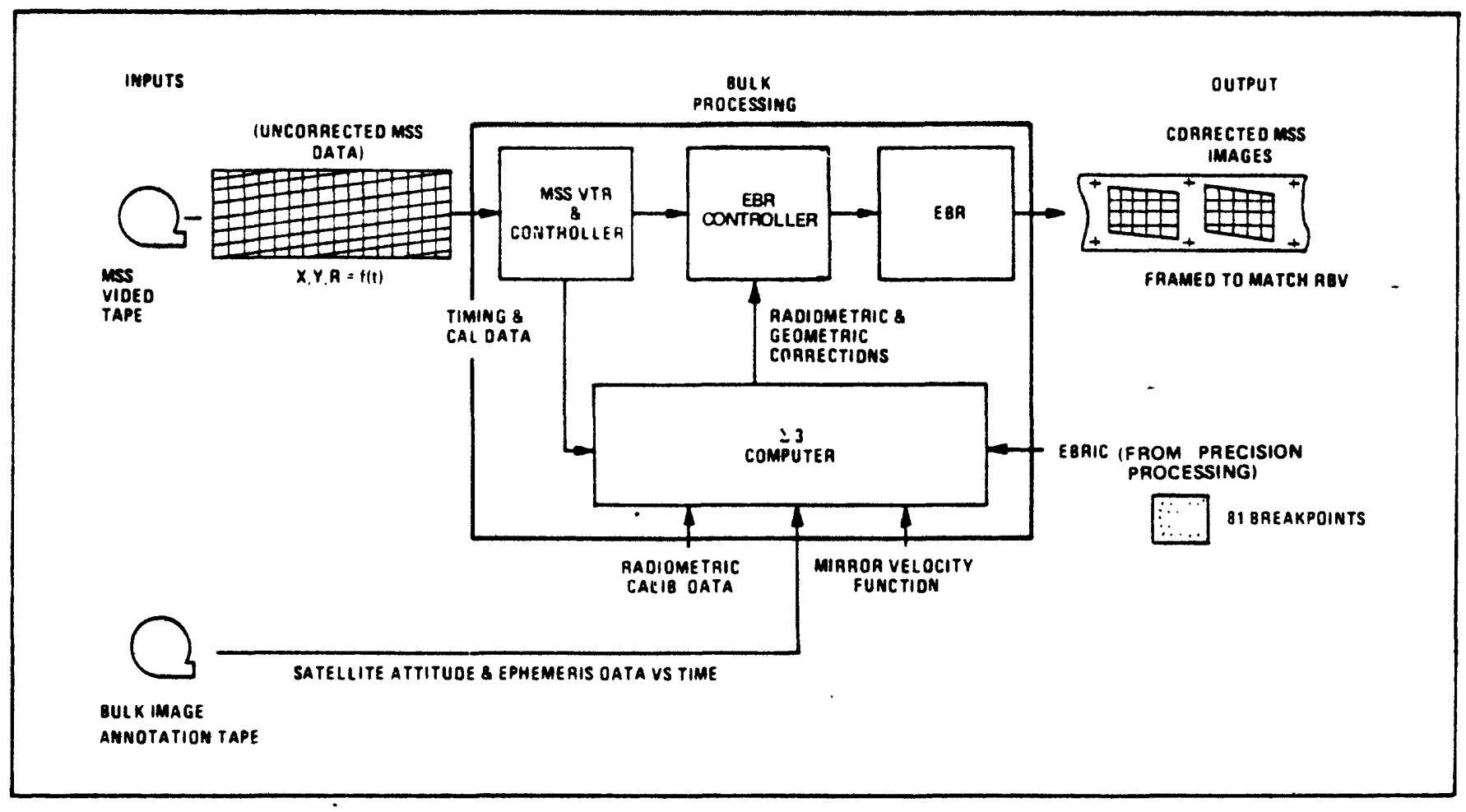

Figure 41: MSS data processing path at the Image Processing Facility at Goddard Space Flight Center. From NASA Landsat Data Users Handbook. 


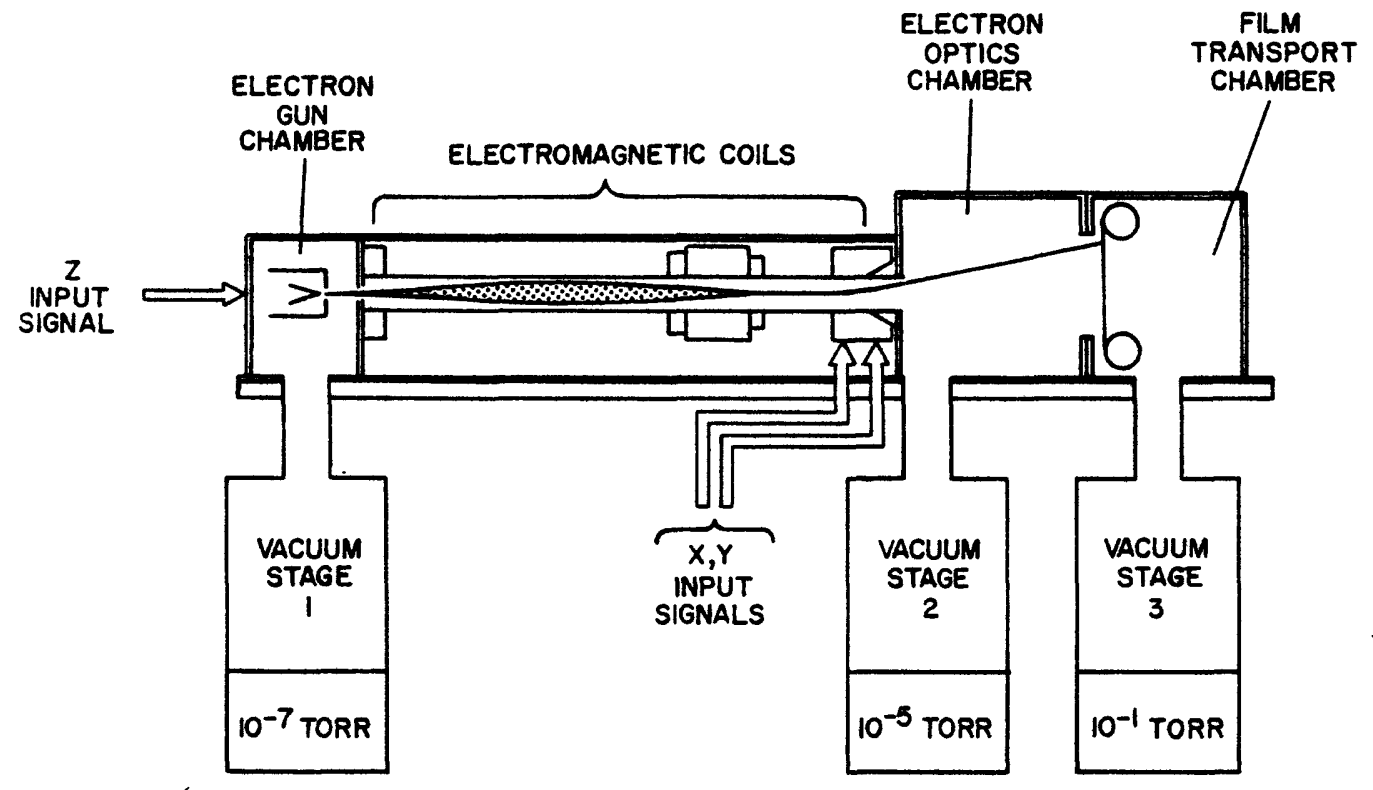

Figure 42: Schematic diagram of the Electron Beam Recorder used to produce Landsat imagery. From Image Graphics, Inc. Brochure.

the Photographic Laboratory. The $70 \mathrm{~mm}$ P-3's are enlarged to $241 \mathrm{~mm}$ size and are printed as fourth generation negatives (N-4's). This enlargement step optically degrades image resolution about $20 \%$. The 1:1,000,000 scale $\mathrm{N}-4^{\prime} \mathrm{s}$ are printed to fifth generation positives $\left(\mathrm{P}-5^{\prime} \mathrm{s}\right)$. Band 4, band 5 , and band 7 fifth-generation positives are pin-registered with color-transparency material in the Photographic Laboratory. Band 4 is exposed on the transparency using blue light, band 5 with green 1ight, and band 7 with red light. The resulting product is a sixth-generation color mastery transparency (CP-6) which is used to produce all other color products. For a complete discussion of photographic techniques used in producing EDC standard products, 
see Lucas, Taranik, and Billingsley (1977).

Landsat computer compatible tapes (CCT's) are produced at GSFC from wide-band video recordings and annotation-tape data. A highdensity digital tape (HDDT) is produced from the video data. The line, and radiometric-calibration-wedge samples (Thomas, 1975, p. D-1). The data are reformatted on the HDDT so bands 4,5 , and 6 have counts from 0 to 127 while band 7 remains at 0 to 63 (fig. 43). Detector response is normalized, but it is seldom perfect, and residual detector striping often remains.

Foreign stations, which receive Landsat data, process their data to imagery and market the data directly to users in their areas. 


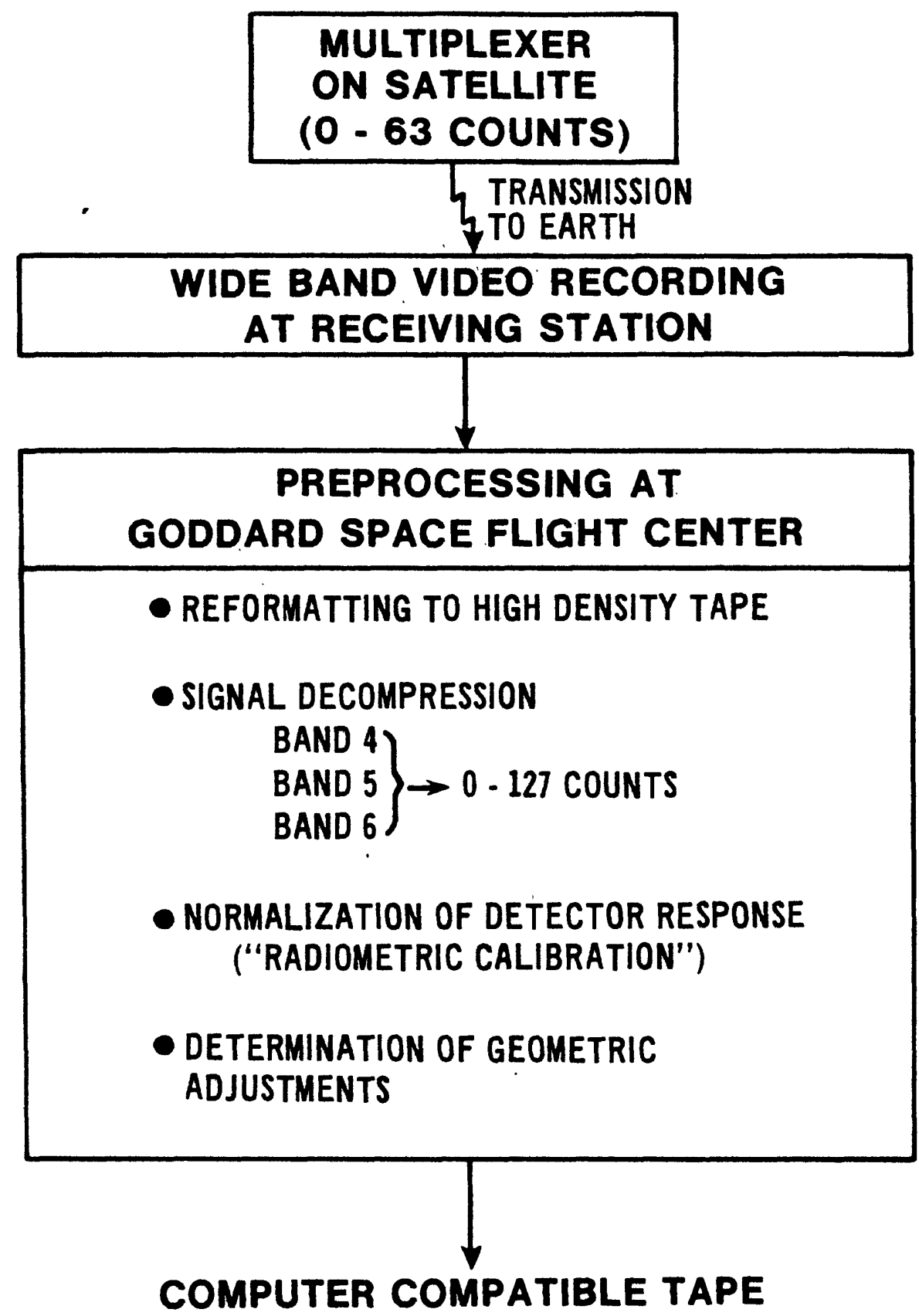

Figure 43: Data processing path for Landsat-1 and -2 computer tapes. PAO Number: E-6199-35 


\section{CHARACTERISTICS OF LANDSAT-1 AND -2 DATA \\ Landsat Imagery}

Coverage of a typical Landsat image is shown in figure 44 . The image deviates from a rectangle by the distance the Earth rotated under the satellite (skew) during the 25 seconds the data were acquired from the top of the scene to the bottom. Lines of latitude and longitude are at an angle with the top and bottom of the image because of the $99^{\circ}$ inclination of the Landsat orbit. The geographic lines are constructed from the bars at the beginning or the end of numbers designating latitude and longitude (fig. 45). The annotation of Landsat-1 and -2 imagery acquired prior to February 1977 is shown in figure 45 .

Table 3 shows the relationships of coverage by a single Landsat scene to coverage by standard 9-by-9-inch (nominal size) aircraft images acquired with a 6-foot focal length, overlap of $60 \%$, and sidelap of $30 \%$.

\section{Landsat Computer Compatible Tapes}

There are 2,340 lines of data on a CCT compared to 2,256 lines of data on a standard Landsat image (figure 46). The EROS Data Center furnishes CCT's in one-tape, 1600 Bit-per-inch format or in two-tape 800 BPI format (fig. 46). Each CCT file contains an identification record, an annotation record, and 780-1ine sets of interleaved video data for all Landsat bands. Both film products and CCT's have the same radiometric corrections applied to the data, and they are both 


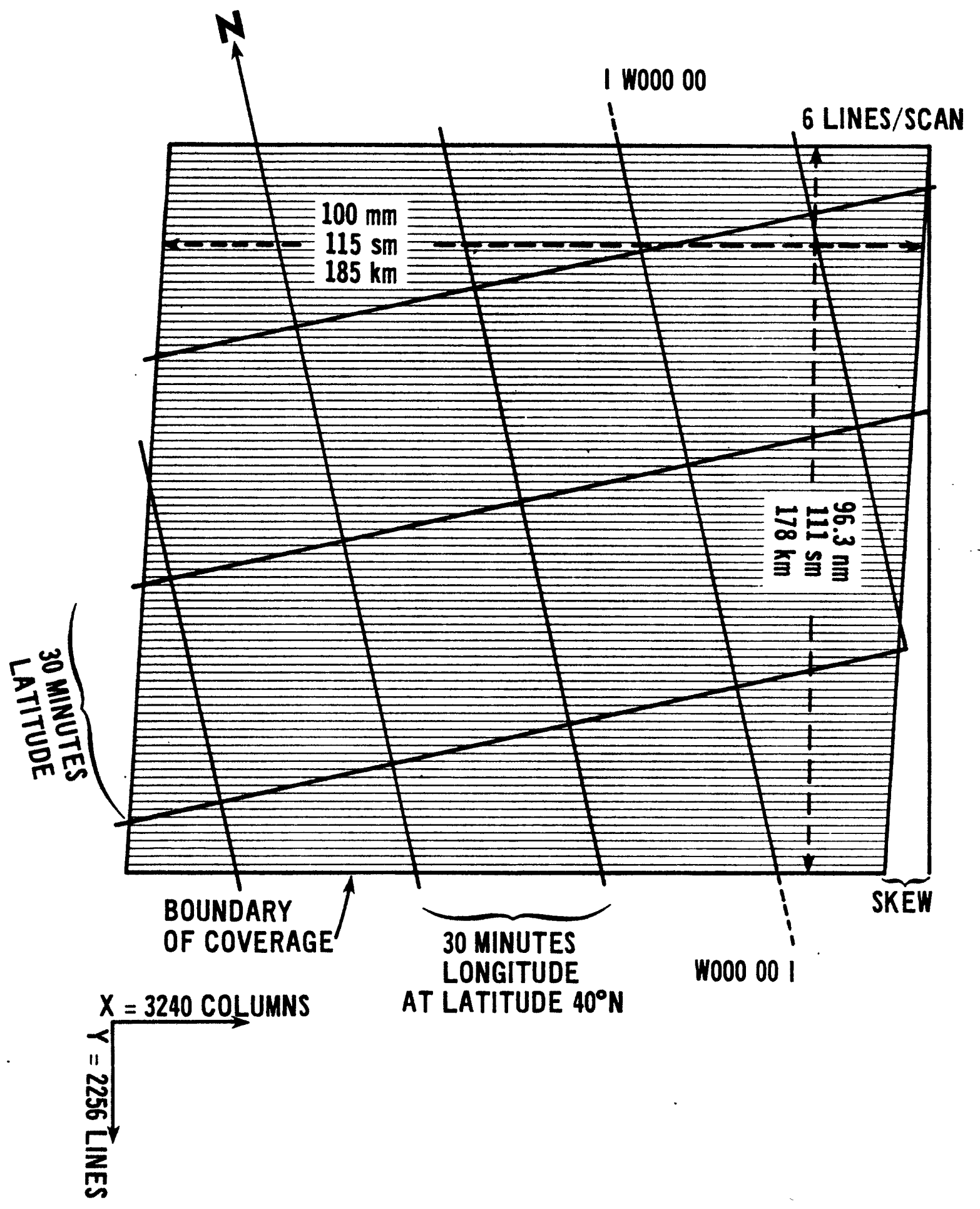

Figure 44: Landsat image coverage. Latitude and longitude lines drawn for an area in Colorado. 


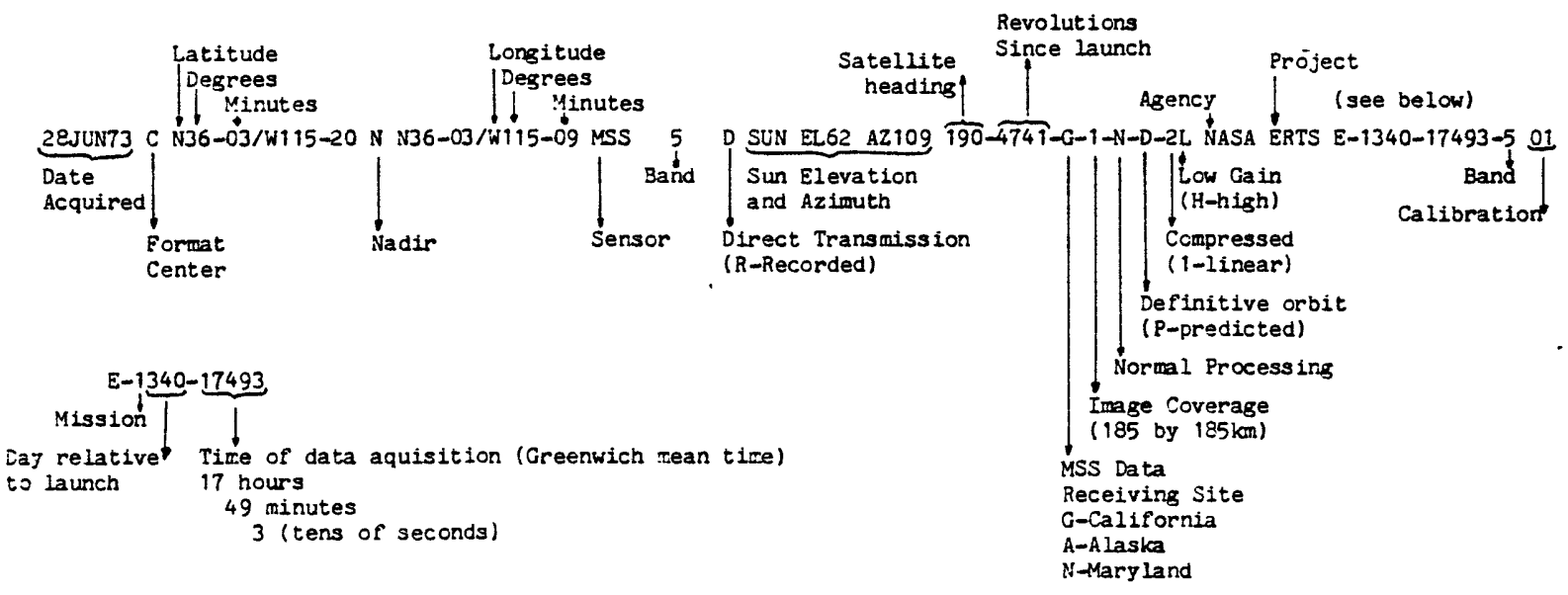

Figure 45: Annotation of Landsat-1 and -2 imagery. 
Table 3: Comparison of Landsat coverage with aircraft coverage

- Coverage of 1 Landsat scene

$185 \mathrm{~km}$ by $178 \mathrm{~km}=32,930$ square kilometers

$115 \mathrm{mi}$ by $111 \mathrm{mi}=12,765$ square miles

-Standard aircraft coverage of 1 Landsat scene

PLATFORM

Low-altitude aircraft

Low-altitude aircraft

High-altitude aircraft

Commercial jet aircraft

Government civilian
$1: 250,000$

\section{SCALE}

$1: 15,000$

$1: 30,000$

$1: 60,000$

$1: 90,000$
NN. PHOTOS

5,000

1,500

300

150

85

30 
adjusted for line length. CCT's are not corrected for variations in mirror-velocity, Earth rotation, or mapping projection (Thomas, 1975, p. 7).

(3240) NOMINAL NUMBER OF COLUMNS

RANGE: 3000 TO 3450 COLUMNS

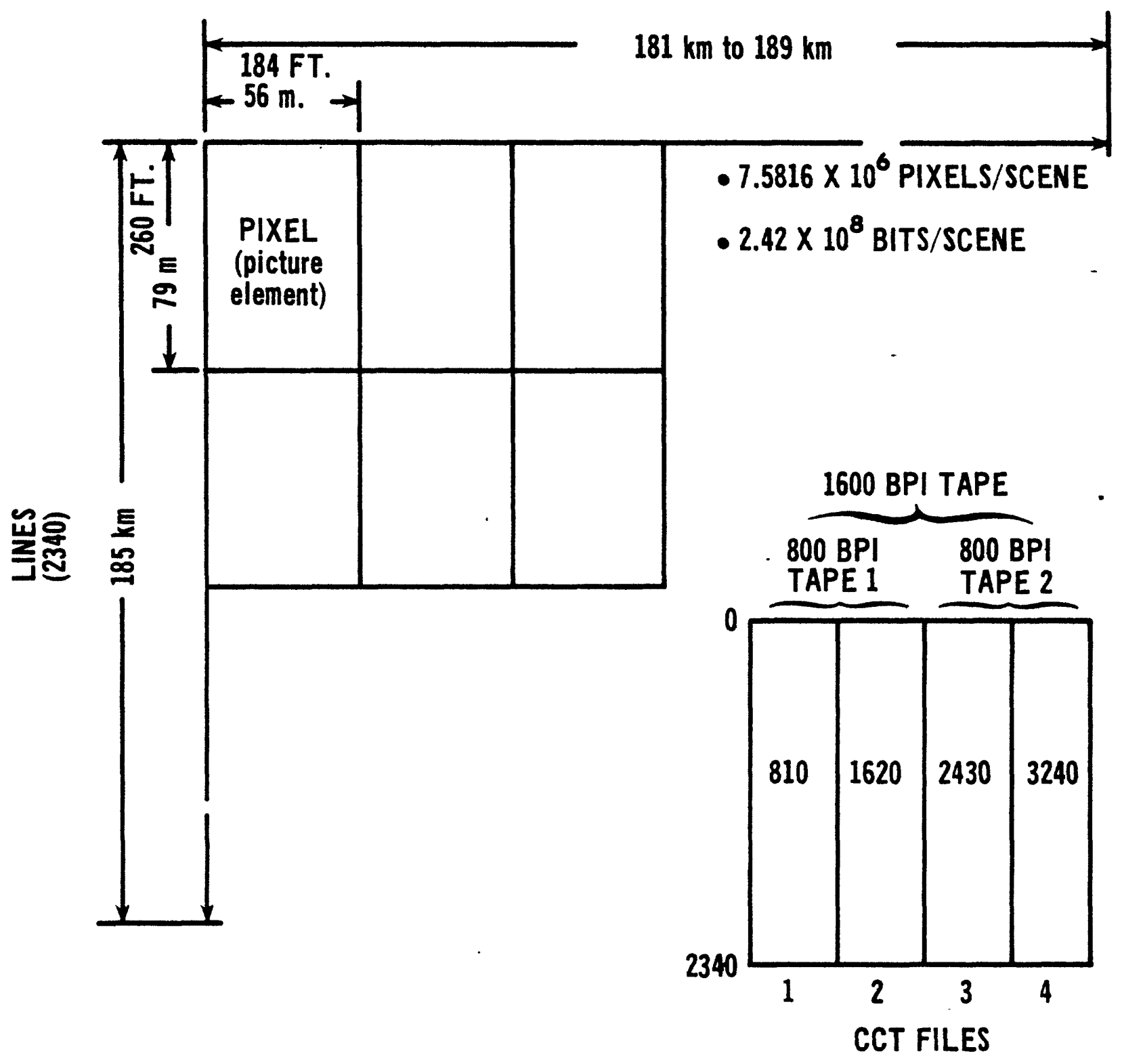

Figure 46: Landsat Computer Compatible Tape format. PAO Number: E-6197-35. 
Computer compatible tapes are being used in increasing numbers by geologists in mineral and petroleum exploration. Digital processing and analysis of computer tapes involves three procedures: data preprocessing, image enhancement, and image classification. Data preprocessing involves correction of system-introduced errors, adjustments for the atmosphere and solar illumination effects, and registration of data. Image enhancement is performed to make spatial patterns, displayed by tones and color, more apparent on imagery. Image classification is performed to delineate multispectral patterns from image data (fig. 47). Interactive multispectral analysis systems allow individual picture elements to be analyzed and displayed using statistical and mathematical processing functions (Taranik, in press). The EROS Data Center has been experimenting with the production of digitally enhanced Landsat products (Rohde, Taranik, and Maas, 1977). The enhanced products are produced from digitally preprocessed Landsat CCT's on a laser-beam recording system. Data for each wavelength band are recorded on $241 \mathrm{~mm}$-wide film over a 1.6 density range. The EROS Data Center digital image enhancement system (EDIES) is an experimental system with a limited output of $2-3$ scenes per day. Products for general users are available under the EDIES program at EDC, and a complete description of the techniques used in producing the enhanced imagery appears in Rohde, Lo, and Poh1, 1978. EDIES will be replaced by a production data processing system during September, 1978. 


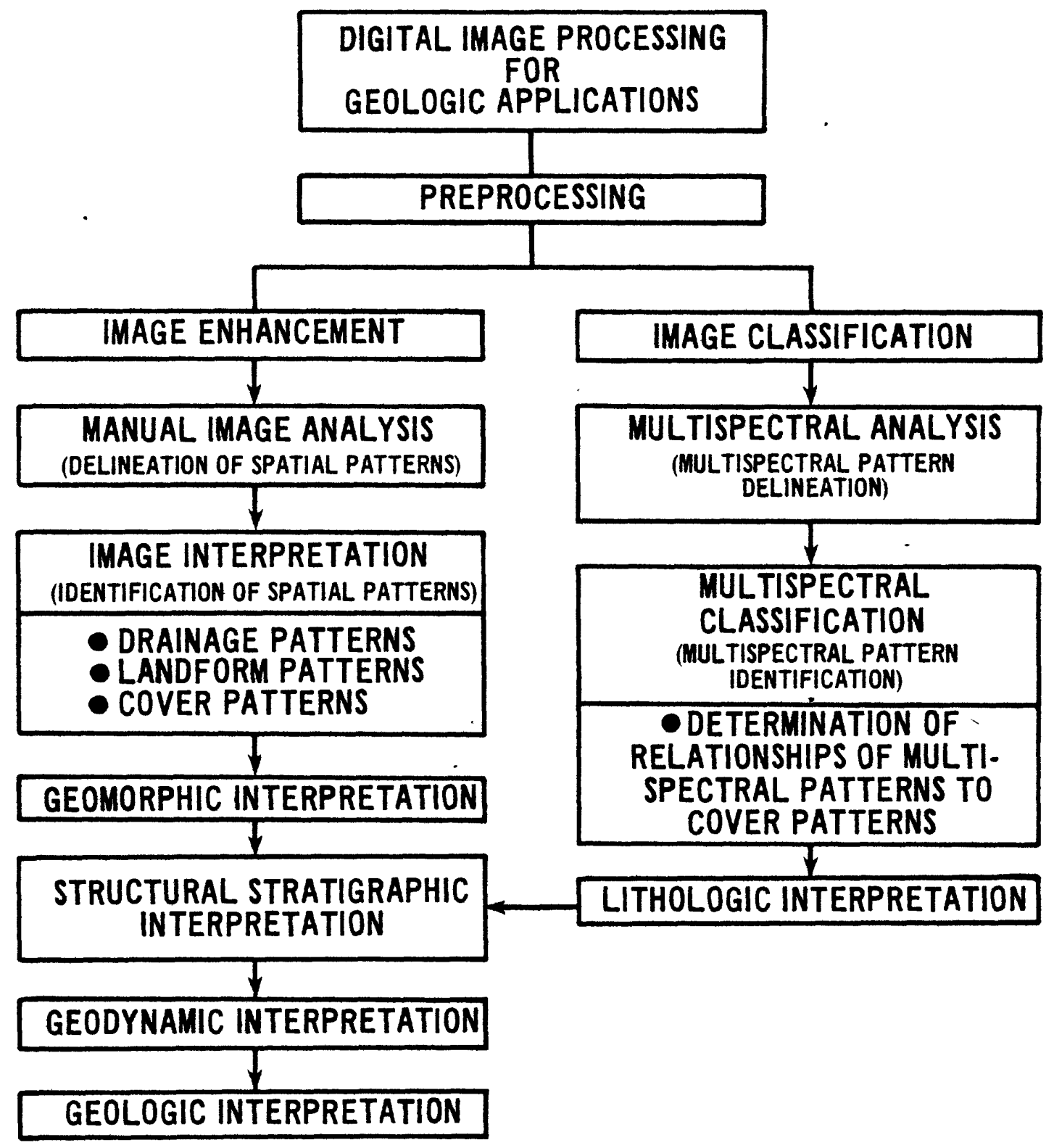

Figure 47: Procedures for digital image processing for geologic applications. PAO Number: E-6211-35 
CHARACTERISTICS OF LANDSAT-C OF IMPORTANCE TO GEOLOGISTS

Landsat-C is scheduled for launch in March, 1978. The satellite will carry the same type of multispectral scanner as Landsats -1 and -2 , except that an additional channel (band 8) will be used to record radiant temperature variations of the Earth's surface. The return beam vidicon sensor will be carried, but in a modified form to provide increased spatial resolution at the expense of spectral resolution and ground coverage of individual frames.

\section{The Multispectral Scanner on Landsat-C :}

The MSS on Landsat-C will have an identical configuration as the instrument used on Landsats -1 and -2 for the channels (bands 4, 5, 6, and 7) which detect solar radiation reflected from the Earth's surface. A thermal sensor has been added on Landsat-C to detect thermal radiation emitted from the Earth's surface at 10.2 to 12.6 micrometers. Most of the thermal radiation detected by this channel came from the sun and was absorbed by the Earth's surface in the visible and near-visible portions of the electromagnetic spectrum (fig. 48). The manner in which absorbed radiation is reradiated by Earth's surface can be described by thermal radiation laws. The amount of radiation from the Earth's surface is approximately a function of the fourth power of its temperature (Stephen-Bolteman Law). The Earth's surface has an average temperature of $300^{\circ}$ Kelvin, and at this temperature emits most of the absorbed radiation at a wavelength of 9.7 micrometer (Wein's Displacement Law). Atmospheric attenuation of radiation from the Earth's surface is minimal in the 10.2 micrometer 
to 12.6 micrometer range (see Tuthil1, Taranik, and Hoyer, 1973, p. 392 - 393 for a complete discussion of principles). Local geothermal anomalies, which are related to heat in the Earth's interior may be detectable on band 8 if they are of large enough size and high enough temperature.
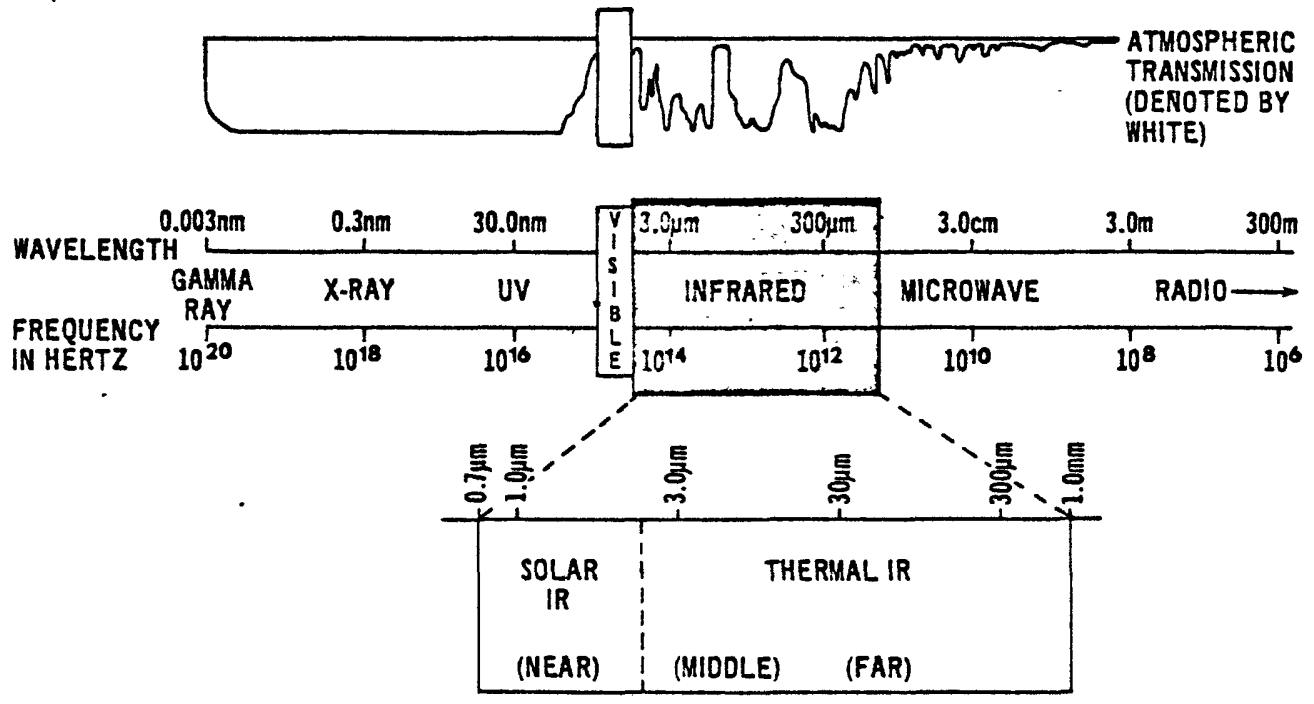

Figure 48: Thermal infrared portion of the electromagnetic spectrum. PAO Number: E-6386-35. 
The two thermal infrared detectors used for band 8 cover the same area on the ground as the six detectors used for each wavelength band in bands $4,5,6$, and 7 . The size of the band 8 fiber optics at the focal plane of the MSS optics is three times the size of the fiber optics for the other MSS bands (fig. 49). This gives band 8 ground instantaneous field of view of $238 \mathrm{~m}$ by $238 \mathrm{~m}$. The voltage-sampling interval for the two thermal detectors results in a band 8 picture element having dimensions $167 \mathrm{~m}$ by $238 \mathrm{~m}$ (fig. 50). The band 8 detector response is specifled to give a $1.52^{\circ} \mathrm{K}$ nolse-equivalent temperature difference at $300^{\circ} \mathrm{K}$. This specification means that an area the size of six football fields must have a radiant temperature difference of $1.0^{\circ} \mathrm{C}$ over background to be detected by band 8 . The gain of band 8 can be linearly adjusted by ground command into 8 different ranges.

\section{The Return-Beam Vidicon}

The return-beam vidicon system utilized on Landsats -1 and -2 is a three-television camera system that records landscape brightness in three wavelength bands (table 2). The operation of each TV camera is similar to the operation of the camera system on Landsat-C. When the camera shutter opens, radiation is focused on a phosphor-coated screen. The screen is scanned by an electron beam to detect minute voltages that are, in turn, amplified by a five-stage multiplier (fig. 51). The three cameras on Landsats-1 and -2 imaged the same $185 \mathrm{~km}$ by $185 \mathrm{~km}$ square area every 25 seconds when the sensor system was operable (fig. 52). For Landsat-C, a decision was made to increase 


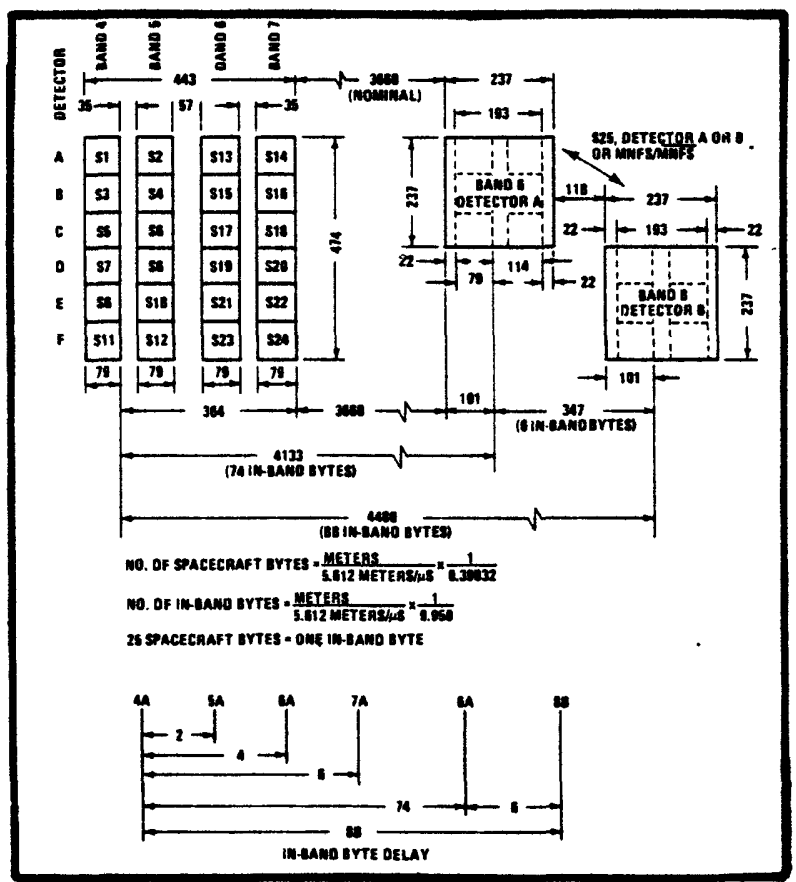

Figure 49: Configuration of the fiber optic bundles in the focal plane of the MSS for Landsat-C. NASA Landsat Data Users Handbook. 


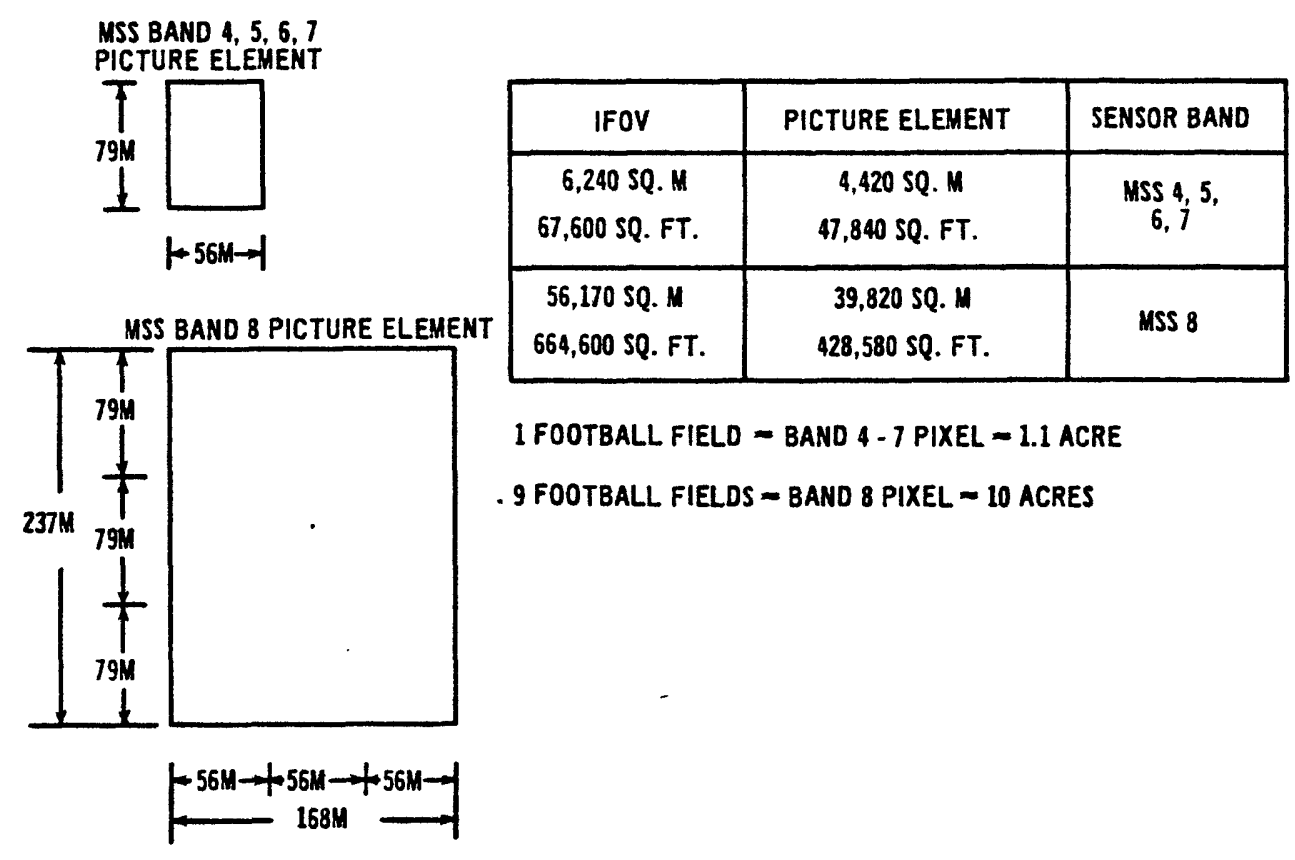

Figure 50: The Landsat-C band 8 picture element compared to picture elements for bands $4,5,6$, and 7. PAO Number: E-6201-35

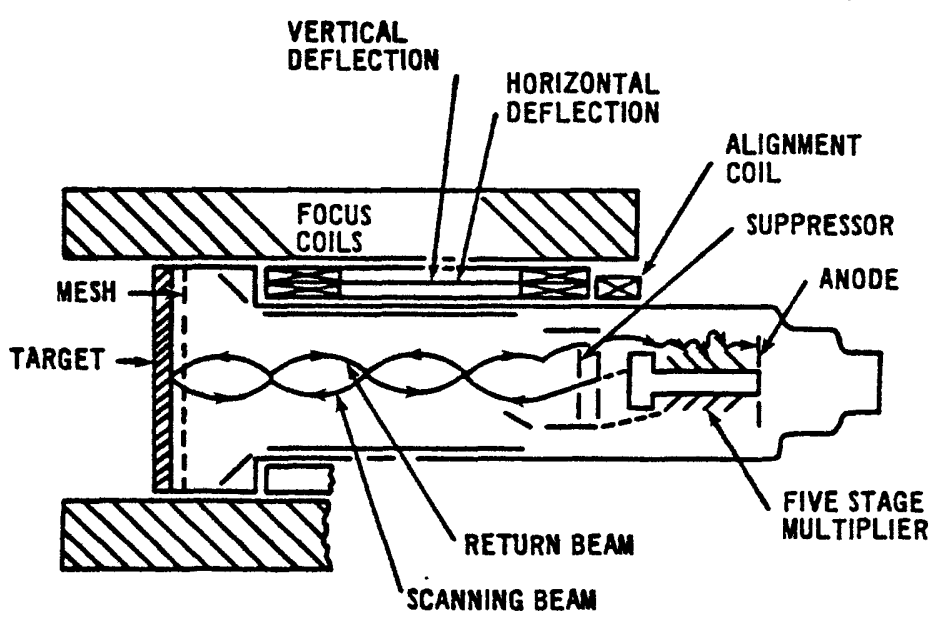

RETURN BEAM VIDICON

Figure 51: Schematic of the RBV system vidicon tube. PAO Number: E-6203-35 
easily analyzed.

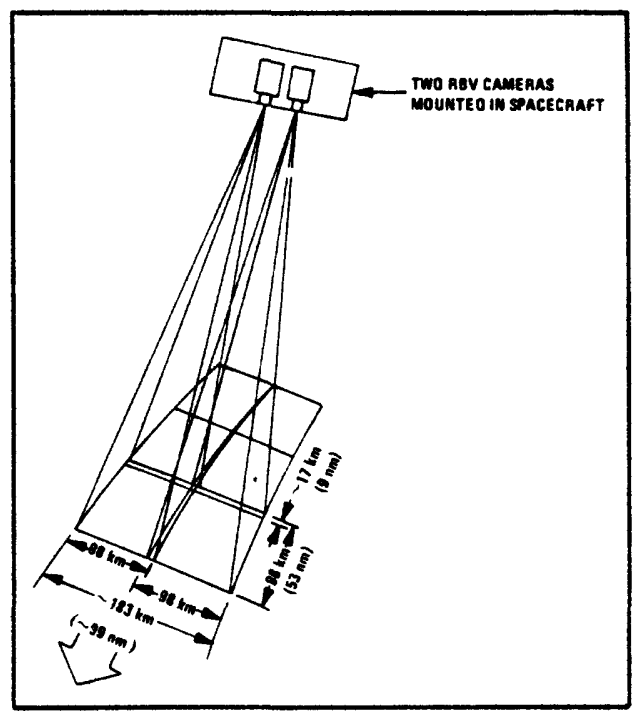

Figure 53: Two-camera RBV system planned for Landsat-C. From NASA Landsat Data Users Handbook. PAO Number: E-6389-35 


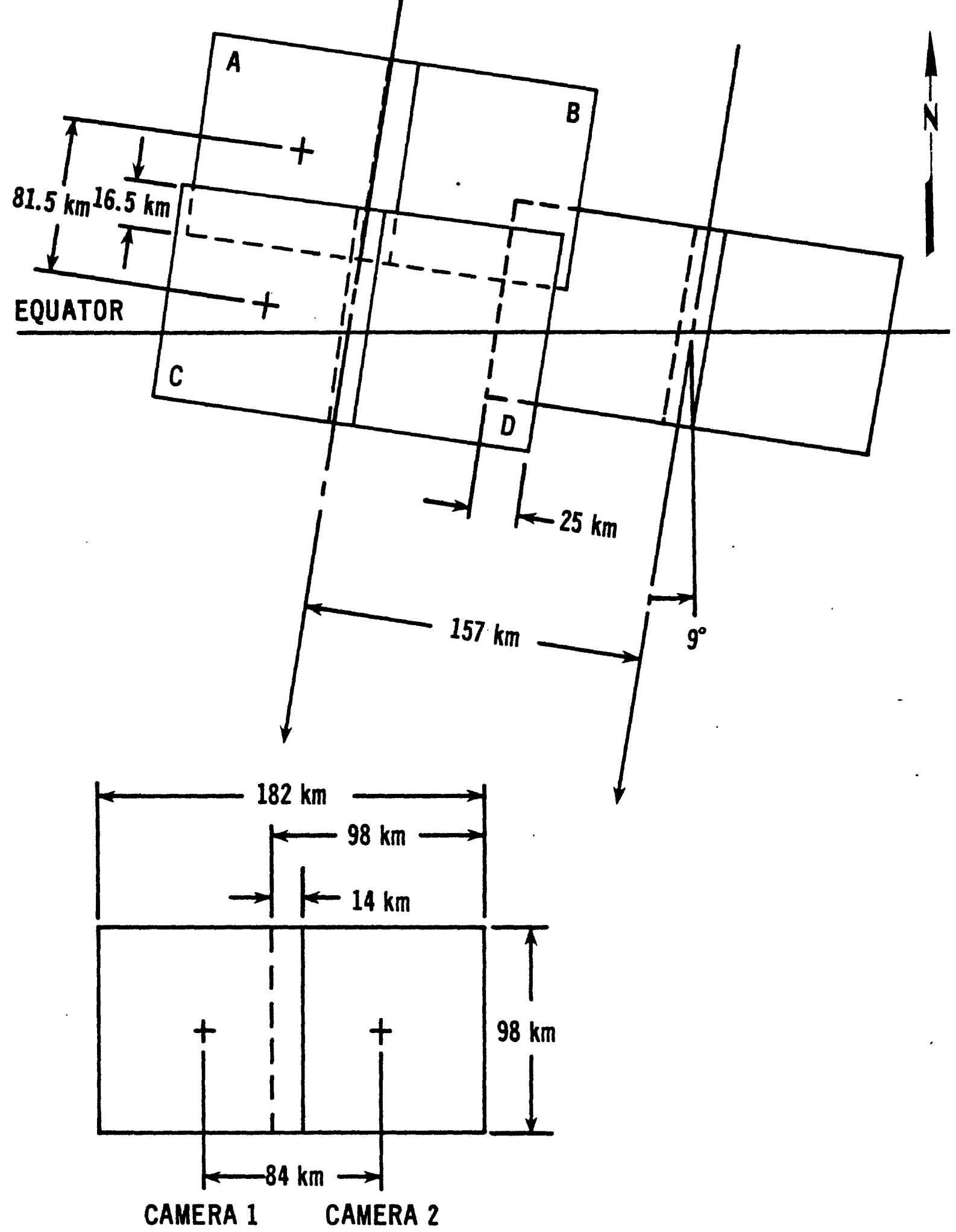

Figure 54: Coverage of the Landsat-C RBV system showing (a) RBV coverage for one Landsat MSS scene and sidelap of data for adjacent swaths; (b) sidelap of data for a single swath using the two camera system. PAO Number: E-6202-35 


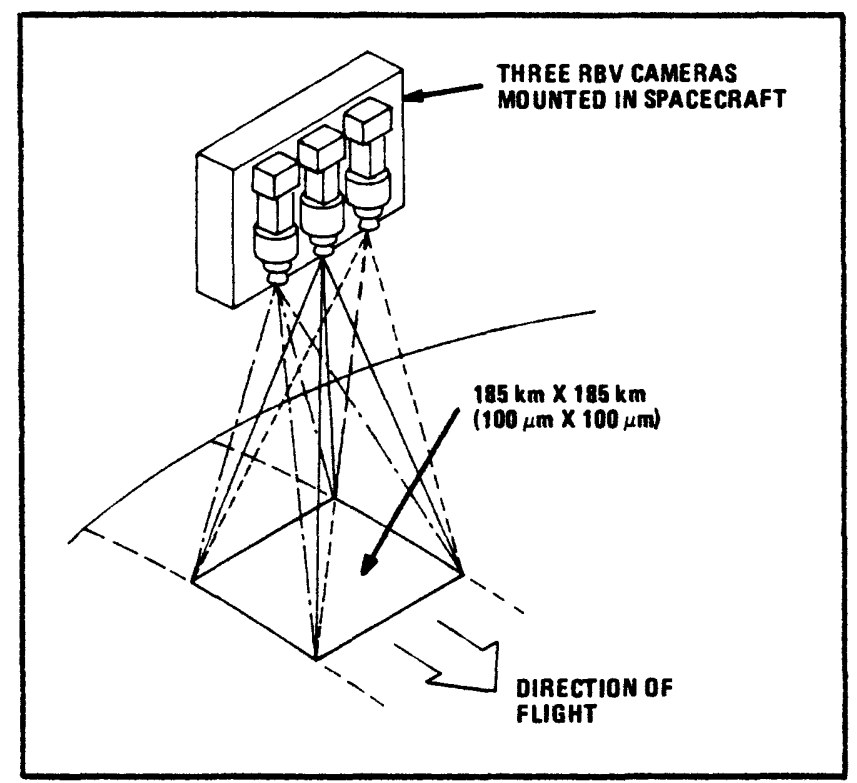

Figure 52: Three camera RBV system on Landsats -1 and -2 . From NASA Landsat Data Users Handbook. . PAO Number: E-6387-35.

$\mathrm{RBV}$ resolution from $80 \mathrm{~m}$ to $40 \mathrm{~m}$ and to use one broad wavelength band from 0.505 micrometers to 0.750 micrometers. The resolution of the RBV was improved by doubling the focal length of the optical system. This reduced areal coverage to one quarter of the area covered by a single RBV camera used on Landsats -1 and -2 . Two cameras are employed on Landsat-C, and they have twice the cycling rate in order to obtain the same areal coverage as the RBV system on Landsats -1 and -2 (fig. 53). Landsat-C coverage is shown in figure 54. The increased spatial resolution of the RBV sensor on the Landsat-C mission may allow drainage and landform patterns to be more 


\section{Landsat-C Data Handling Plan}

A proposed data handling plan for Landsat-C data is shown in figure 55. Film products and CCT's for all Landsat data produced in the Landsat-C time period will be produced at the EROS Data Center (EDC) for the general user community. The Data Center will produce master film products using the EROS Data Center digital image processing system (EDIPS). This system will produce master images at $241 \mathrm{~mm}$ size using a high-resolution Laser Beam Recording System. Digital preprocessing will be used to correct imperfections in the original data, and image enhancement will be used to record the data on film in a manner that facilitates efficient reproduction of film products. When the EDIPS system becomes operational in 1978, the EDIES experimental system will be discontinued in March, 1978. Landsat-C MSS and RBV data will be recorded at 1:1,000,000 and 1:500,000 scales respectively. Four RBV images are required to cover the same area as one MSS image.

\section{LANDSAT $-D$}

Current plans (January, 1978) for Landsat-D define the prime sensor system as a six (6) or possibly seven (7) channel multispectral scanner called the thematic mapper (TM). Most of the spectral bands on the TM were selected for agricultural applications. The possible seven channels are:

$\begin{array}{lll}\text { Channel 1 } & 0.45-0.52 \mu \mathrm{m} & \text { visible blue-green } \\ \text { Channel 2 } & 0.52-0.60 \mu \mathrm{m} & \text { visible green } \\ \text { Channel 3 } & 0.63-0.69 \mu \mathrm{m} & \text { visible red }\end{array}$




$\begin{array}{lll}\text { Channel } 4 & 0.76-0.90 \mu \mathrm{m} & \text { invisible solar infrared } \\ \text { Channel } 5 & 1.55-1.75 \mu \mathrm{m} & \text { invisible solar infrared } \\ \text { (Channel 6) } & 2.08-2.35 \mu \mathrm{m} & \text { (solar infrared) } 1 / \\ \text { Channel } 7 & 10.4-12.5 \mathrm{~m} & \text { thermal infrared }\end{array}$

Other recommendations include using the MSS on Landsat-C as a backup sensor and as a basis for comparison of the new TM data. The TM would then be used in an experimental mode over selected areas.

A tentative data handling plan for Landsat data distributed to the EROS Data Center in the Landsat-D time frame is shown in figure 56. Domestic communication satellites will probably be used in the 1980's to relay data from remote antennas to Goddard Space Flight Center and from there to the EROS Data Center. This data relay system should make data available to users in a matter of a few days.

NASA has also proposed a satellite data relay system which would allow instantaneous relay of data acquired from nearly any part of the world to the United States. With this system, data could be collected over any area without the use of tape recorders. The proposed system would relay data directly from Earth observations satellites, to a geosynchronous satellite, and then to a recelving station in White Sands, New Mexico. Preprocessing would be done in White Sands, and then data would be relayed to a national data archive. This system should provide better coverage of forelgn areas.

1/ Proposed by geologists for research in rock spectral reflectance. 


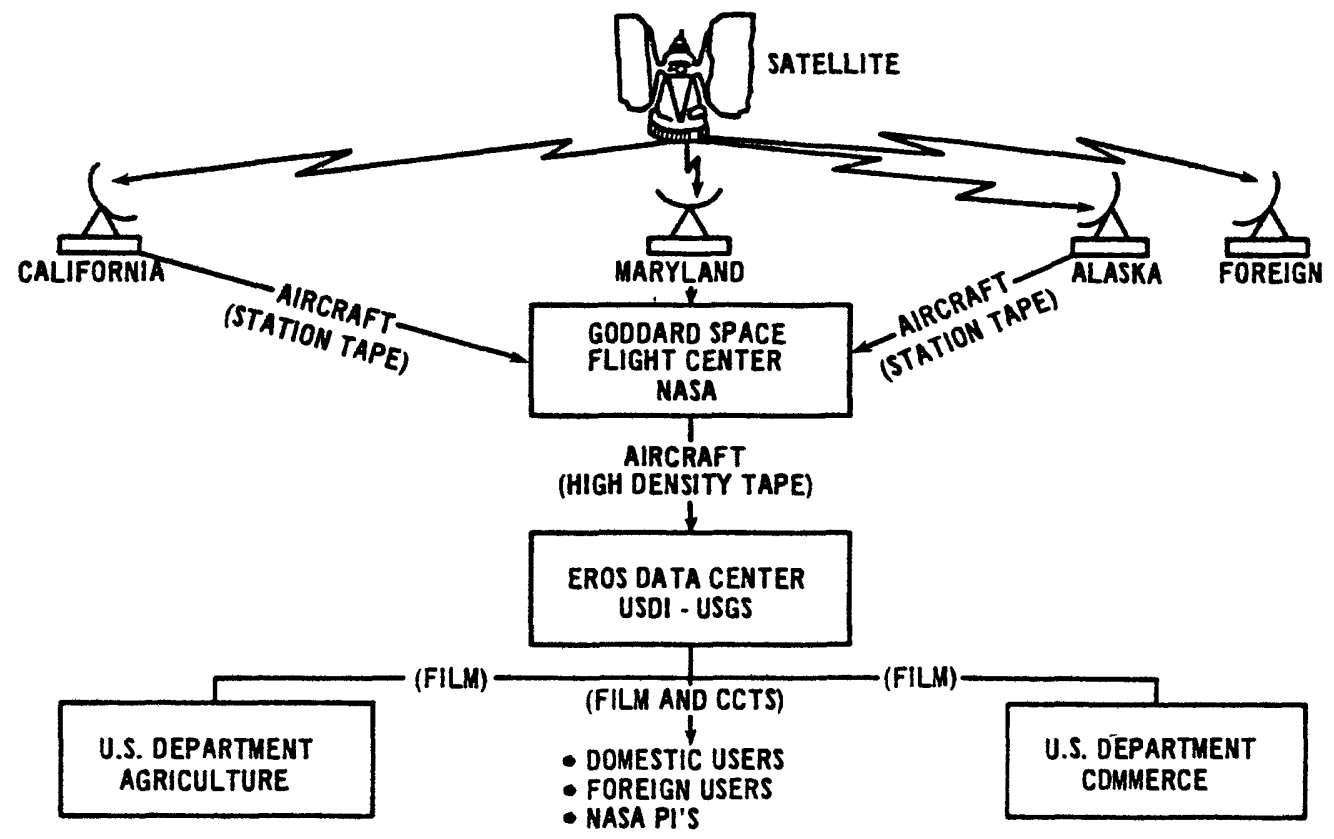

Figure 55: Proposed data handling plan for Landsat-C data. PAO Number: E-6205-35 


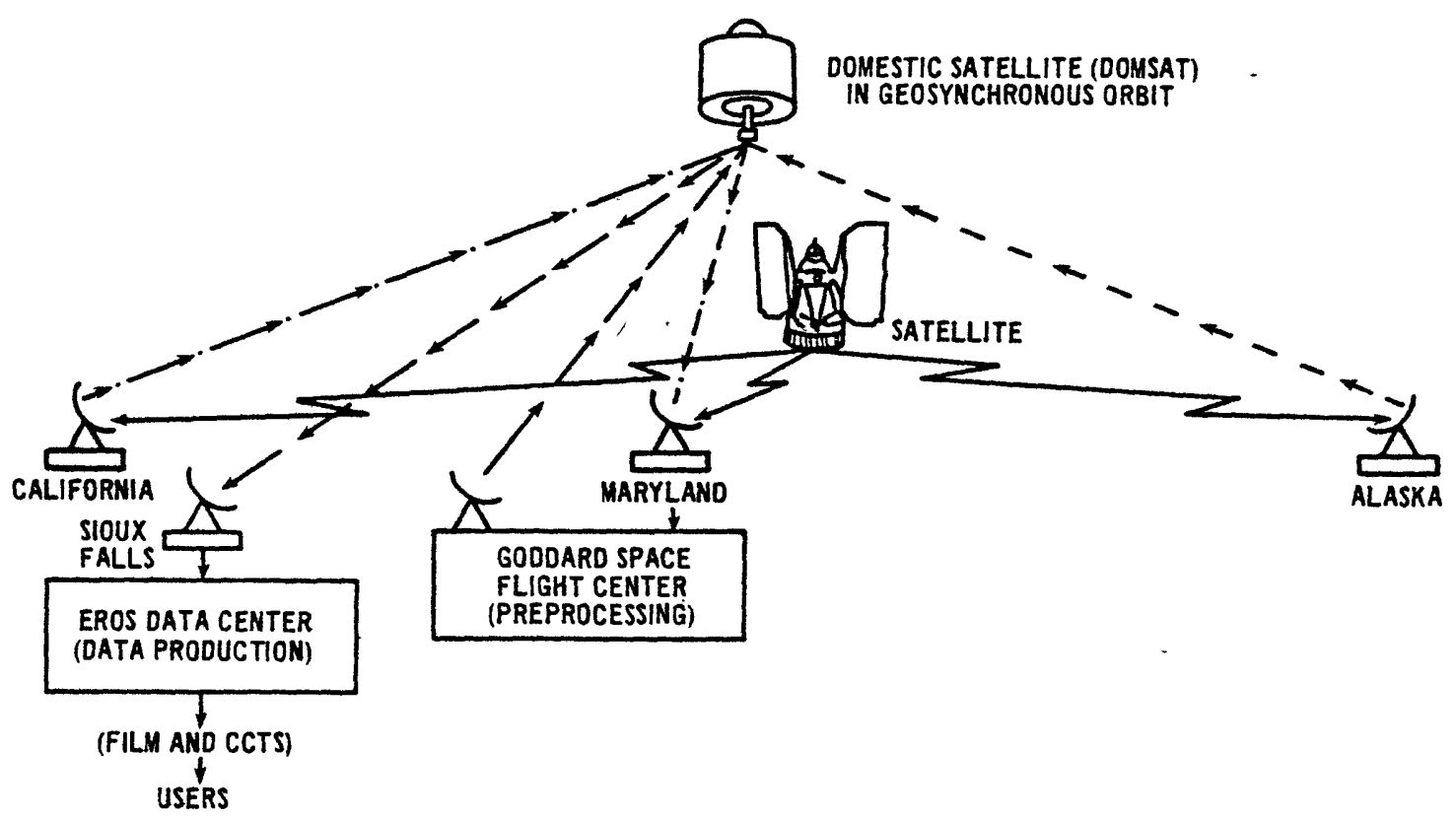

Figure 56: Possible data handling plan for data produced in the Landsat-D time frame. PAO Number: E-6206-35 


\section{REFERENCES CITED}

Lucas, J.R., and Taranik, J.V., 1977, Late Wisconsinan deglaciation of the upper Midwest interpreted from a springtime Landsat Mosaic, in Internat. symposium on remote sensing of environment, Michigan, 11th, 1977, Proc.: Ann Arbor, Mich., Environmental Research Inst. Michigan.

Lucas, J.R., and Taranik, J.V., and Billingsley, F.C., 1977, Photooptical enhancement of Landsat imagery for land-use analysis in south-central Iowa: NASA Technical Type II, Report 5, National Technical Information Service, 105 p.

Morrison, R.B., 1976, Glacial geology and solls in the midwestern United States, in Williams and Carter, eds., ERTS-1 a new window to our planet: U.S. Geol. Survey, Prof. Paper 929, p. 67-71.

Norwood. V.T., Fernella, L.R., and Tadler, G.A., 1972, Multispectral Scanner system for ERTS: Hughes Aircraft Report HS3245214, Final Report, v. I.

Ragland, T.E., and Chavez, P.S., 1976, EDIPS (EROS digital image processing system): In 2nd William T. Pecora Memorlal Symposium, Sioux Fal1s, South Dakota, October 1976, Am. Soc. Photogram., Falls Church, VA, p. 47-63.

Rohde, W.G., Taranik, J.V., and Maas, K.A., 1977, EROS Data Center digital enhancement techniques for Landsat data, in Internat. symposium on remote sensing of environment, Michigan, 11th, 1977, Proc.: Ann Arbor, Mich., Environmental Research Inst. Michigan. 
Rohde, W.G., Lo, J.K., and Pohl, R.A., 1978, EROS Data Center Landsat digital enhancement techniques and imagery availability, in symposium on remote sensing science and technology, Canada (February 1977), Proc.: Ottawa, Canada, Canadian Journal of Remote Sensing.

Taranik, J.V., (in press), Principles of computer processing of Landsat data for geologic applications, U.S. Geological Survey, Open-File Report, in press, 1978, $40 \mathrm{p}$.

Taranik, J.V., and Trautwein, C.M., 1977, Integration of geological remote sensing techniques in subsurface analysis, in LeRoy and LeRoy, eds., Subsurface geology, petroleum-mining-construction: Colorado School of Mines, Golden, Colorado, p. 767 - 787. Thomas, V.L., 1975, Generation and physical characteristics of the Landsat-1 and -2 MSS computer compatible tapes: U.S. Nat1. Aeronautics and Space Admin., Goddard Space Flight Center, Doc. X563-75-223, November 1975, Greenbelt, Maryland (bound, variously paged).

Tuthill, S.J., Taranik, J.V., and Hoyer, B.E., 1973, Thermal remote sensing on the Mississippi River in Iowa: in ACHIE Symposium Series, N. 129, v. 69, American Institute of Chemical Engineers, 345 East 47 Street, New York, p. 391 - 400 .

U.S. National Aeronautics and Space Administration, Goddard Space Flight Center, 1976, Landsat data users handbook: U.S. Nat1. Aeronautics and Space Admin., Goddard Space Flight Center, Doc. 76SD4258, September 2, 1976 (1oose-leaf, variously paged). 
Welch, Robin, and Lo, C.P., 1977, Height measurements from satellite images: Photogram. Eng. Remote Sensing, v. 43, no. 10, p. $1233-1241$. 